\title{
Quantum Chemical Simulations Reveal Acetylene-Based Growth Mechanisms in the Chemical Vapor Deposition Synthesis of Carbon Nanotubes
}

\author{
Ying Wang, ${ }^{1,2}$ Xingfa Gao, ${ }^{3}$ Hu-Jun Qian, ${ }^{4}$ Yasuhito Ohta,${ }^{5}$ Xiaona Wu, ${ }^{1}$ Gyula Eres, ${ }^{6}$ \\ Keiji Morokuma, ${ }^{5,7}$ and Stephan Irle $*^{1}$
}

(1) WPI-Institute of Transformative Bio-Molecules and Department of Chemistry, Graduate School of Science, Nagoya University, Nagoya 464-8602, Japan

(2) State Key Laboratory of Rare Earth Resource Utilization, Changchun Institute of Applied Chemistry, Chinese Academy of Sciences, Changchun, 130022, China

(3) Key Laboratory for Biomedical Effects of Nanomaterials and Nanosafety, Institute of High Energy Physics, Chinese Academy of Sciences, Beijing, 100049, China

(4) Institute of Theoretical Chemistry, State Key Laboratory of Theoretical and Computational Chemistry, Jilin University, Changchun 130023, China

(5) Fukui Institute for Fundamental Chemistry, Kyoto University, Kyoto, 606-8103, Japan

(6) Materials Science and Technology Division, Oak Ridge National Laboratory, Oak Ridge, Tennessee 37831, United States

(7) Cherry L. Emerson Center for Scientific Computation and Department of Chemistry, Emory University, Atlanta, GA, 30322, United States

\footnotetext{
* Corresponding Authors. Tel. Numbers \& E-Mail addresses: +81-52-747-6397 \& sirle@chem.nagoya-u.ac.jp (S.I.); +81-75-711-7843 (204) \& keiji.morokuma@emory.edu (K.M.)
} 
Abstract: Nonequilibrium quantum chemical molecular dynamics (QM/MD) simulation of early stages in the nucleation process of carbon nanotubes from acetylene feedstock on an $\mathrm{Fe}_{38}$ cluster was performed based on the density-functional tight-binding (DFTB) potential. Representative chemical reactions were studied by complimentary static DFTB and density functional theory (DFT) calculations. Oligomerization and cross-linking reactions between carbon chains were found as the main reaction pathways similar to that suggested in previous experimental work. The calculations highlight the inhibiting effect of hydrogen for the condensation of carbon ring networks, and a propensity for hydrogen disproportionation, thus enriching the hydrogen content in already hydrogen-rich species and abstracting hydrogen content in already hydrogen-deficient clusters. The ethynyl radical $\mathrm{C}_{2} \mathrm{H}$ was found as a reactive, yet continually regenerated species, facilitating hydrogen transfer reactions across the hydrocarbon clusters. The nonequilibrium QM/MD simulations show the prevalence of a pentagon-first nucleation mechanism where hydrogen may take the role of one "arm" of an $\mathrm{sp}^{2}$ carbon Y-junction. The results challenge the importance of the metal carbide formation for SWCNT cap nucleation in the VLS model and suggest possible alternative routes following hydrogen-abstraction acetylene addition (HACA)-like mechanisms commonly discussed in combustion synthesis. 


\section{Introduction}

The synthesis of carbon nanotubes (CNTs) [1] and in particular single-walled CNTs (SWCNTs) [2, 3] has been the focus of much scientific interest because of their unique physical [4] and chemical [5] properties, as well as their potential technological applications [6]. The use of nanoparticle transition metal catalysts is considered critical in large-scale SWCNT synthesis such as the one reported in reference [7]. However, non-transition metal catalysts were also found to be effective catalysts in SWCNT growth [8]. There are two different ways to synthesize SWCNTs in the presence of metal catalyst nanoparticles: pure carbon-based methods employing various high-temperature $(>3000 \mathrm{~K})$ techniques to vaporize graphite or other carbonaceous material mixed with metal or metal oxides, and catalytic chemical vapor deposition (CCVD) methods for gaseous carbon-containing compounds that operate at lower temperatures ( 500 to 1500 Kelvin). The former methods mainly employ carbon arc discharge $[2,3,9]$ and laser evaporation techniques $[10,11]$, while CCVD syntheses either use a floating catalyst/hydrocarbon source setup (e.g. $\mathrm{Fe}(\mathrm{CO})_{5}[12]$ and ferrocene [13]), or employ substrates with deposited metal catalyst particles that are flushed with a mixture of inert gas and hydrocarbon feedstock. The CCVD synthesis often benefits from adding small quantities of $\mathrm{H}_{2}$ [14] and/or etching agents such as ammonia [15]. The carbon feedstock species may contain only one carbon atom ( $\mathrm{C} 1 \mathrm{compounds})$ such as in methane [16-18] or methanol [19], but more frequently it contains two (C2 compounds) such as in ethane $[18,20]$, ethylene $[18,21,22]$, acetylene $[23,24]$, and ethanol [25], and not so frequently more than two carbon atoms [26].

Acetylene is known to dissociate on $\mathrm{Fe}(100)$ at temperatures as low as $100 \mathrm{~K}$ [27], and to significantly accelerate the CCVD synthesis even in small quantities [28], to the point 
that the enhanced reactivity of its primary decomposition product, namely the ethynyl radical $\mathrm{C}_{2} \mathrm{H}$, may cause passivation of the catalyst [23]. Interestingly, acetylene was also identified as the key growth precursor in plasma-enhanced CVD of the C1 compound methane [29]. In 2005, a molecular beam study (for suppressing secondary gas phase reactions) established that only heterogeneous surface reactions contribute to carbon deposition in CNT growth [30]. A subsequent experiment confirmed that $\mathrm{C}_{2} \mathrm{H}_{2}$ is by far the most efficient carbon source [31]. The other classes of carbon containing molecules, small hydrocarbons, aromatic ring species and $\mathrm{CO}$ did not result in CNT growth, meaning that they do not interact strongly with the surface. In CCVD synthesis these molecules produce CNT growth because of the secondary gas phase reactions that form more reactive surface species [32]. Thus, it was shown that acetylene-like species must form as intermediates to grow CNTs, making the study of acetylene-based CCVD highly important for the understanding of processes occurring in hydrocarbon-based SWCNT CCVD syntheses.

The mechanism of SWCNT nucleation on transition metal catalyst particles is conventionally assumed to consist of the following succession of stages [33]: 1) decomposition of the hydrocarbon feedstock gas into $\mathrm{H}_{2}$ and active carbon species directly on the metal particle, 2) dissolution of the active carbon into the metal particle, producing liquid or surface-molten metal carbide until supersaturation with carbon is reached, and finally 3) carbon precipitation on the surface of the metal carbide particle. At this stage it is assumed that semi-fullerenes form on the curved catalyst surface, which are believed to satisfy the isolated pentagon rule [34] and to have perfectly established $(n, m)$ chirality at their edges, representing the initial cap of the growing SWCNT [19, 33]. This sequence of stages is named vapor-liquid-solid (VLS) [35, 36] mechanism, after the phase transitions undergone 
by the carbon atoms. Its applicability to CCVD-based SWCNT synthesis is widely assumed, but upon closer inspection, actual support from experiment is surprisingly weak. In fact, it was recently shown that CNTs can grow on metal oxide nanoparticles [8], metal particles that do not dissolve carbon [37], semiconductor particles [38], and even without any attached nanoparticles in the vapor phase [39]. These findings clearly demonstrate that the VLS mechanism is not a general mechanism for describing carbon nanotube growth in a CVD environment. In the following, we will briefly summarize other recent findings conflicting with the VLS mechanism for CCVD SWCNT growth.

An important issue that arises even before stage 1 is the precursor gas chemistry. Preheating the precursor was found to positively affect the crystallinity of carbon nanotubes synthesized at low temperatures [22], and its chemical composition was found to influence $(n, m)$ distribution [40] and growth rates [41]. Even the gas flow direction seems to play an important role for sustained, large-scale SWCNT forest growth [7]. Thus, it seems reasonable to assume the occurrence of at least some pyrolytic hydrocarbon feedstock decomposition prior to its adsorption on the catalyst surface. Concerning the catalytic hydrocarbon decomposition of stage 1, the transformation of the feedstock into active carbon is assumed to occur on the metal catalyst surface. However, presently nothing is known about the hydrogen elimination mechanism at elevated temperature, other than the fact that SWCNT growth is strongly associated with the production of $\mathrm{H}_{2}$ [17] and of volatile organic compounds (VOCs) and/or polycyclic aromatic hydrocarbon species (PAHs) as common byproducts $[22,42,43]$.

The formation of the metal carbide phase in stage 2 and, therefore the chemical nature of the metal catalyst particle is often drawn into question [30, 44-47]. Even more 
importantly, the necessity of the formation of an initial carbon cap has been questioned as well [48], despite the fact that occasionally environmental TEM (ETEM) studies record images of nascent carbon nanocaps $[45,49]$. The central critique by Eres et al. is that a predominant cap nucleation seems incompatible with SWCNT growth, since $\mathrm{sp}^{2}$ carbon network formation significantly reduces the concentration of active carbon on the catalyst surface [48]. The argument is based on experimentally recorded growth kinetics of vertically aligned nanotube arrays (VANTAs), suggesting that acetylene undergoes molecular self-assembly into progressively large carbon structures such as polyyne chains, graphenes, and only at a final stage into CNTs. The reported presence of the aforementioned VOCs and PAHs found in CCVD exhaust $[22,42,43]$ is consistent with this hypothesis. If this is true, one might consider the well-established hydrogen abstraction-acetylene addition (HACA) mechanism established for PAH formation [50-52].

In summary, it is therefore reasonable to explore why the importance of the VLS mechanism in CCVD synthesis of SWCNTs is overstated. In order to address the controversial issues concerning stages 1 and 3 , it is necessary to take into account the molecular composition of the hydrocarbon feedstock; all previous theoretical studies of SWCNT nucleation and growth have always employed pure metal-carbon systems only. Reviews of past key theoretical studies are given in references [53-55], while references [56-61] represent some recent theoretical works on metal-carbon systems, illustrating the profuse activity to understand the SWCNT formation mechanism at an atomic level. In contrast, in this work we present the first quantum chemical simulation of the difficult-to-study [53-55] hydrocarbon decomposition and $\mathrm{sp}^{2}$ carbon network formation on a metal nanoparticle, using nonequilibrium QM/MD simulations of acetylene CCVD SWCNT 
synthesis and density functional theory (DFT) calculations for reaction energy profiles. To directly investigate the role of hydrogen in the early stage of the nanotube nucleation process, we mostly followed the methodology of our previous simulations using $\mathrm{C}_{2}$ feedstock [46], simply replacing $\mathrm{C}_{2}$ by acetylene, $\mathrm{C}_{2} \mathrm{H}_{2}$. However, the slow dynamics related to hydrogen abstraction reactions requires some modifications to our simulation strategy, as will be detailed below. 


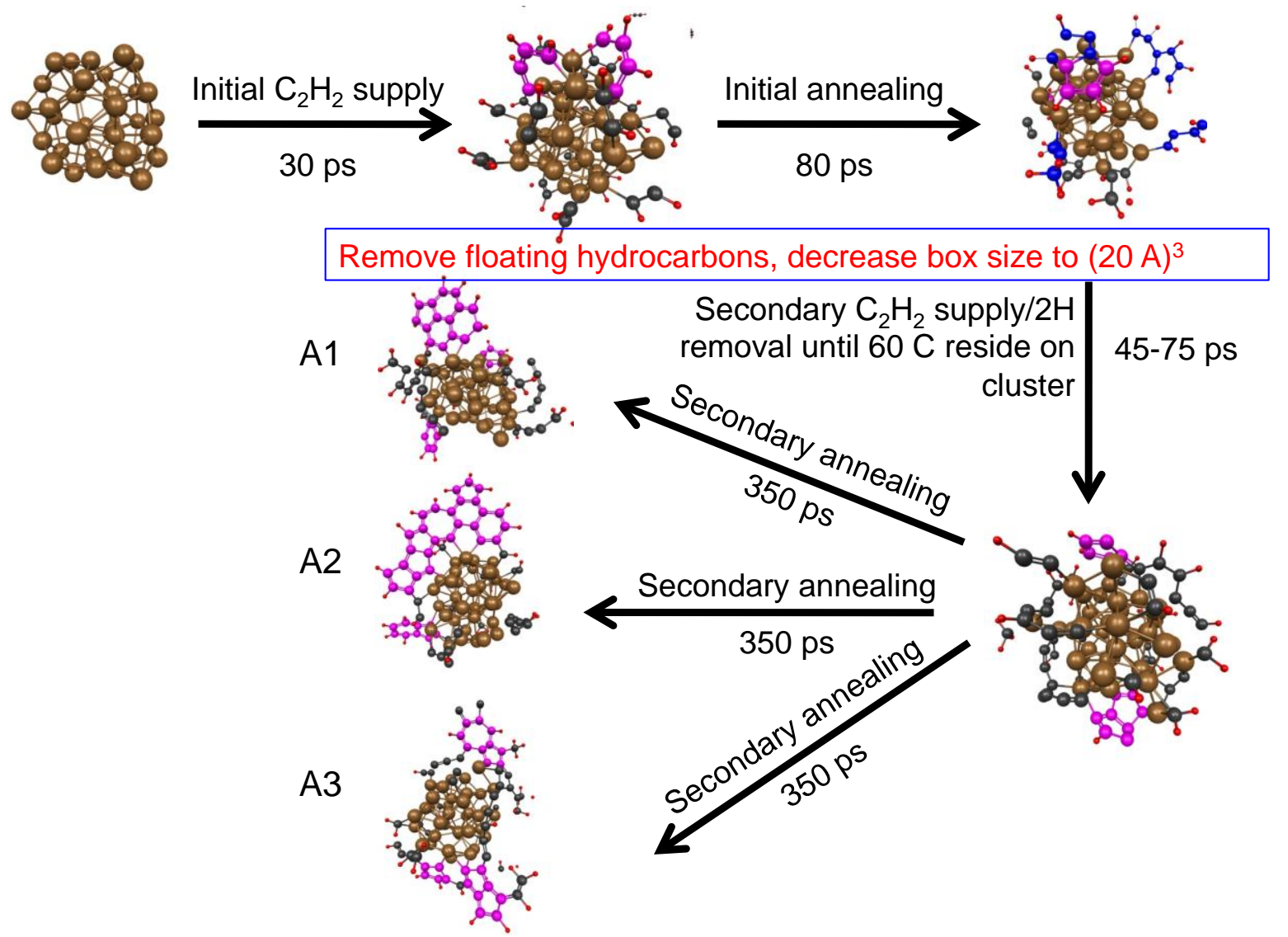

Figure 1 - Schematic depictions of nonequilibrium QM/MD simulations of acetylene CCVD SWCNT growth. Trajectory A was selected as an example.

\section{Computational Details}

\subsection{Density-functional tight-binding (DFTB) method}

The density-functional tight-binding (DFTB) method $[62,63]$ is the central method adopted in the present study. DFTB is an approximate density functional theory method based on the tight binding approach and utilizes an optimized minimal LCAO Slater-type all valence basis set in combination with two-center approximation for Hamiltonian matrix elements. 
The employed parameter sets are publically available and described in reference [64]. The DFTB quantum chemical potential is ideally suited to bridge a gap in the field of reactive molecular dynamics simulations between reactive force field approaches and first principles density functional theory (DFT) methods; it is several orders of magnitude faster than the latter but in contrast to the former it explicitly includes electronic effects. It also possesses a hierarchy of different approximations to electron-electron interactions, ranging from zero order (complete neglect) [62] over a spin-unpolarized self-consistent-charge DFTB (SCC-DFTB) second-order approximation [63] to the spin-polarized self-consistent-charge (SDFTB) second-order approximation [65]. The DFTB and SCC-DFTB methods have therefore been employed by us in the study of carbon nanostructure formation before [66-69]. Since the density of states (DOS) near the Fermi level is very high for metal nanoparticles and an average of various spin states needs to be dealt with, we employed the spin-unpolarized SCC-DFTB method in this as in all previous, metal-related studies. In the following paragraphs, SCC-DFTB will be referred to simply as "DFTB" for brevity. The high DOS requires the employment of a Fermi-Dirac electron occupation distribution function with finite electronic temperature $T_{\mathrm{e}}[70]$. The analytical first order and numerical second order (when needed) geometrical energy derivatives were consequently computed for the Mermin free energy which includes the electronic entropy arising from the fractional orbital occupations [71]. Concerning the somewhat arbitrary choice of this parameter, we found that a value of $T_{\mathrm{e}}=10,000 \mathrm{~K}$, corresponding to $k_{B} T_{\mathrm{e}} \sim 0.87 \mathrm{eV}$, is comparable to the half-width of the $3 d$ band of the present iron cluster and, therefore, flexible enough to cover changes of this band due to chemical processes. The quantum chemical calculations were carried out with a modified FORTRAN program package developed by Frauenheim, Seifert, and Elstner 
$[62,63]$.

\subsection{Nonequilibrium molecular dynamics simulations}

Periodic boundary conditions (PBC) were imposed with a cubic box of size $(100 \AA)^{3}$ up to 110 ps and a $(20 \AA)^{3}$ box size afterwards. The electronic energy levels were evaluated using the Gamma-point approximation. Direct nonequilibrium MD simulations were performed based on the DFTB first order geometrical energy derivatives computed on the fly for the Mermin potential energy. For MD time propagation, we employed a velocity Verlet integrator with a time interval $d t$ of $0.5 \mathrm{fs}$, which is able to maintain total MD energy in microcanonical simulations of an acetylene molecule in the gas phase within a few $\mathrm{kcal} / \mathrm{mol}$. The nuclear temperature $T_{\mathrm{n}}$ was controlled by connecting the ensemble particles to a Nose-Hoover chain thermostat [72] with chain length 3 , and constantly set to $T_{\mathrm{n}}=1500 \mathrm{~K}$. For the iron nanoparticle we chose a small $\mathrm{Fe}_{38}$ cluster with its atoms initially arranged in an fcc crystal lattice, identical to the one used by us previously in references [73-76]. Following exactly the same methodology as in our study of carbon cap nucleation from $\mathrm{C}_{2}$ molecules, we first equilibrated the fcc-Fe ${ }_{38}$ icosahedral cluster at $1500 \mathrm{~K}$ for $10 \mathrm{ps}$, and extracted ten geometries randomly from this MD run from the time interval between 5 and 10 ps. These ten geometries were the initial starting structures for ten trajectories, which we label A-J. During the first $30 \mathrm{ps}$ of the production nonequilibrium MD trajectories, we supplied individual $\mathrm{C}_{2} \mathrm{H}_{2}$ molecules in 1 ps time intervals at random positions around the metal cluster. Each new acetylene molecules was created inside a spherical shell around the center of mass of the $\mathrm{Fe}_{38}$ cluster, with inner and outer radii of $10.0 \AA$ and $12.0 \AA$, 
respectively. The velocity vectors of the $\mathrm{C}_{2} \mathrm{H}_{2}$ constituent atoms were directed to the $\mathrm{Fe}_{38}$ center of mass, with magnitudes drawn from a Maxwell-Boltzmann distribution at $T_{\mathrm{n}}=1500$ $\mathrm{K}\left(k_{b} T_{\mathrm{n}} \sim 0.13 \mathrm{eV}\right) . \quad$ After these $30 \mathrm{ps}$ "supply simulations", we annealed the resulting clusters at the same temperature. Since the resulting carbon nanostructures on the nanoparticle did not show any signature of carbon ring formation, we decided to depart from our previously employed strategy in the all-carbon simulations [46], and started secondary $\mathrm{C}_{2} \mathrm{H}_{2}$ supply/H removal simulations after only 80 ps of annealing, by shooting one $\mathrm{C}_{2} \mathrm{H}_{2}$ every $5 \mathrm{ps}$ and at the same time randomly deleting two $\mathrm{H}$ in the system, until the total number of $\mathrm{C}$ reached 60 or 61 . We then created three replica of each trajectory by randomizing nuclear velocities, and performed secondary annealing simulations of the resulting 30 trajectories for $350 \mathrm{ps}$.

\subsection{Density functional theory benchmark calculations}

In order to verify the accuracy of the DFTB method with respect to key chemical reaction processes, we performed geometry optimizations and computed vibrational frequencies for simplified model reactions without PBC at the above-described level of DFTB theory for stationary points [reactants, first-order saddle points (TSs), and products] on the Mermin free energy surface. After locating the appropriate TS, we computed its minimum energy paths (MEP) connecting the corresponding reactant and products by the intrinsic reaction coordinate (IRC) method [77]. These calculations were technically performed by connecting the Paderborn DFTB code to Gaussian 03 [78], using its "external" functionality. Once the reaction energy profile was established in this manner, we computed first principles 
density functional theory (DFT) single-point energies at DFTB-optimized geometries using the SIESTA code [79]. The density functional employed in these benchmark calculations was the spin-polarized generalized gradient approximation (GGA) exchange-correlation density functional referred to as $\operatorname{PBE}[80,81]$, in combination with a double- $\zeta$ plus polarization basis set (DZP), norm-conserving pseudopotentials [82], and a mesh cutoff of $250 \mathrm{Ry}$. In these calculations the total spin is allowed to vary during the search for the electronic ground state wavefunction. We employed periodic boundary conditions (PBC) with a cubic unit cell of $24 \AA \times 24 \AA \times 24 \AA$ using the $\Gamma$ point approximation. To achieve SCF convergence of the Kohn Sham equations, we employed an electronic temperature of $500 \mathrm{~K}$, and the convergence criterion for the total electronic energy was set to $3 \times 10^{-4} \mathrm{eV}$. The energies obtained at this level of theory are referred to as PBE/DZP//DFTB.

\section{Results and Discussions}

\subsection{Scheme of simulations}

Our nonequilibrium QM/MD simulations cover a time period of more than half a nanosecond at the constant temperature of $1500 \mathrm{~K}$. As mentioned above, they consist of four stages: an initial supply stage of 30 ps where $\mathrm{C}_{2} \mathrm{H}_{2}$ molecules are added to an $\mathrm{Fe}_{38}$ cluster, a subsequent first annealing stage for $80 \mathrm{ps}$, a $\mathrm{C}_{2} \mathrm{H}_{2}$ secondary supply/H removal stage of 40 to $75 \mathrm{ps}$ during which the number of carbon atoms on the cluster is increased and the H/C ratio is decreased, and a subsequent second annealing stage for 350 ps. A schematic diagram of our simulations is shown in Figure 1. While the temporal separation of supply and 
annealing stages is obviously artificial, its merits are that: It allows a systematic comparison of our previous analogous $\mathrm{C}_{2}$-supply simulations [46] with the present $\mathrm{C}_{2} \mathrm{H}_{2}$ as feedstock, and to "disentangle" the processes occurring during acetylene supply, annealing, and hydrogen abstraction to facilitate analysis. Ten independent trajectories labeled alphabetically A-J were created from the naked $\mathrm{Fe}_{38}$ cluster equilibration run, and each of the ten primary trajectories was parent to a set of three secondary trajectories at the secondary annealing stage to increase statistical significance, as described in the Methods Section. From the trajectories we extracted hydrocarbon cluster growth and hydrogen migration dynamics with associated key chemical reaction steps, and analyzed them using reaction energy profiles for simplified model systems containing a limited number of hydrocarbon species on the $\mathrm{Fe}_{38}$ cluster. After secondary supply and growth, we observe the formation of mainly three different types of $\mathrm{sp}^{2}$ carbon network structures: large polycondensated PAHs, islands of smaller PAH fragments, and cap-like structures. 
a)
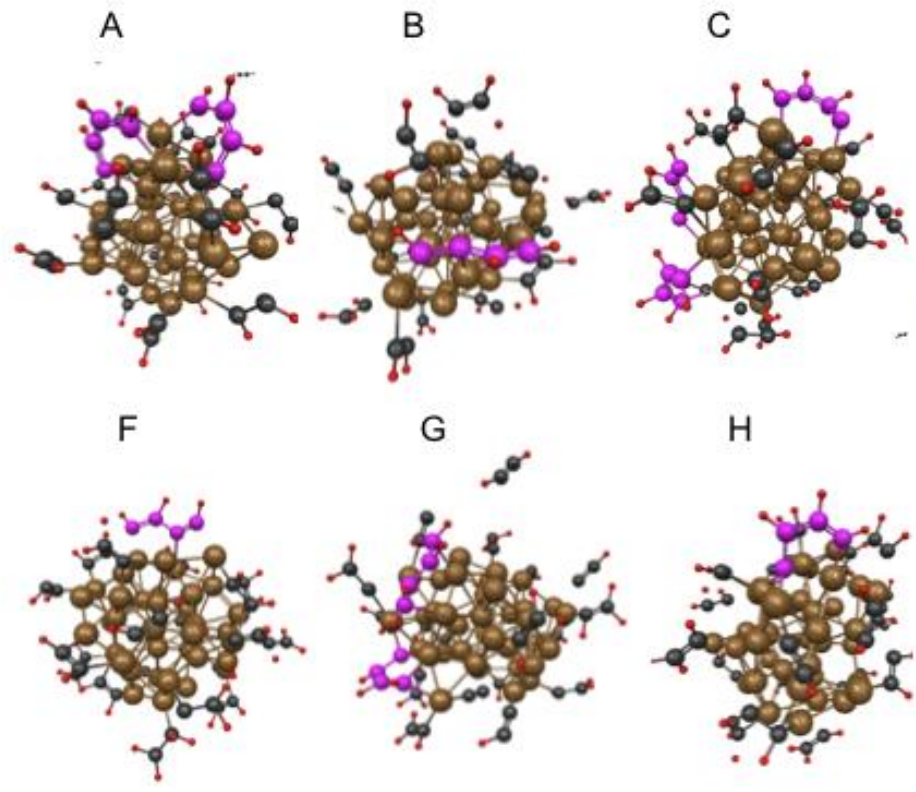

$\mathrm{H}$

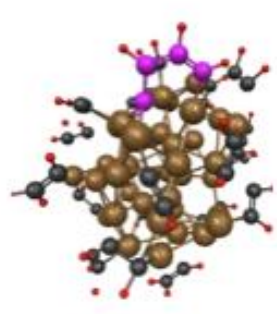

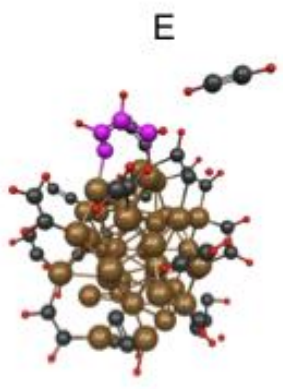

$\mathrm{J}$

b)

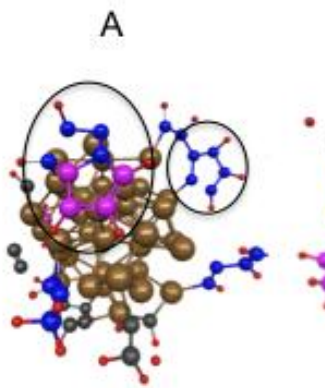

B

C
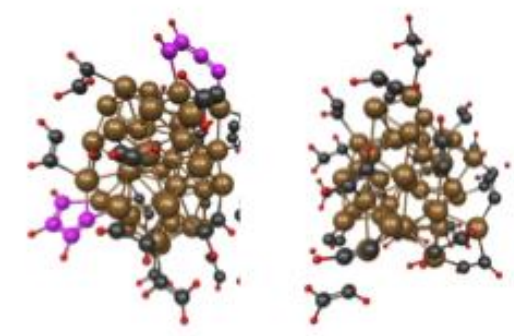

pas
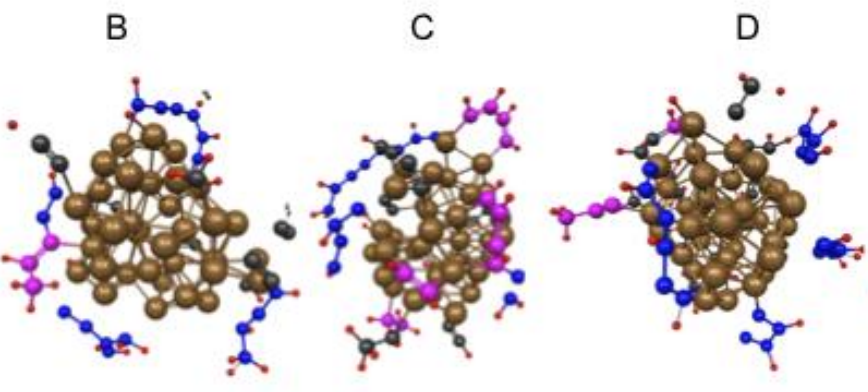

E

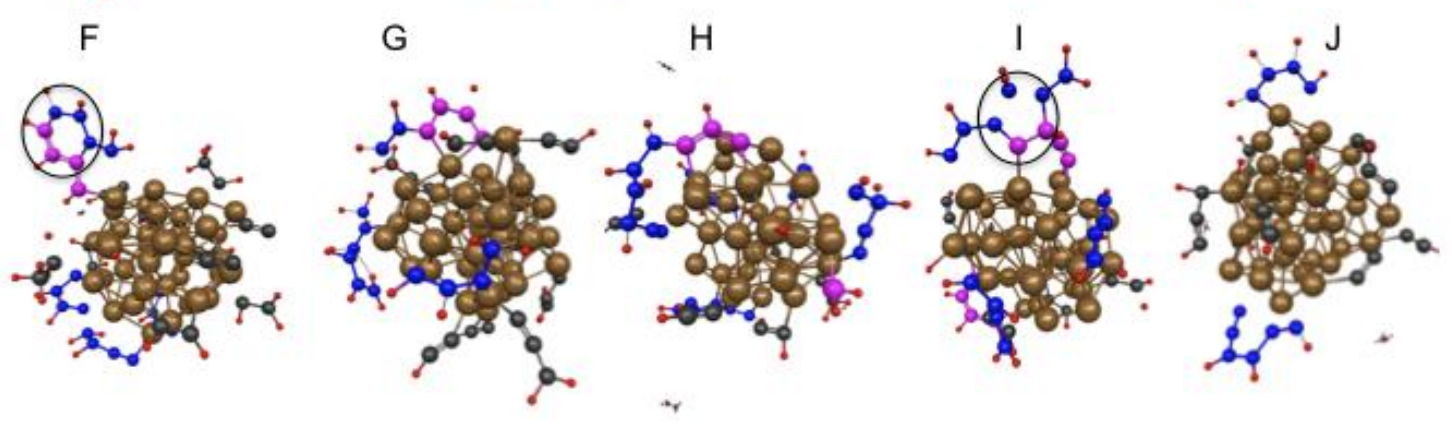

Figure 2 - Snapshots of 10 trajectories a) after 30 ps $\mathrm{C}_{2} \mathrm{H}_{2}$ supply simulations, and b) after 110 ps at the end of the annealing simulations. The purple spheres indicate hydrocarbon chains formed after the supply of $30 \mathrm{C}_{2} \mathrm{H}_{2}$. The blue spheres indicate newly formed hydrocarbon chains and rings after 80 ps the annealing simulations. Black circles highlight newly formed carbon rings. 


\subsection{Nature of acetylene-iron complexes}

In the present simulations, the chemisorbed acetylene molecules "stick" on the surface as a side-on ocomplex, where the carbon atoms are coordinated to iron atoms via obonds, the triple bond was formally reduced to a double bond with a bond length of about 1.37 to $1.40 \AA$, and both carbons form HCC angles of around $120^{\circ}$. This binding mode has been well studied on various iron surfaces $[83,84]$, and our results are in good agreement with the earlier first principles calculations. The complex also resembles closely the side-on coordination of $\mathrm{C}_{2}$ molecules on an iron particle [46, 85]. At both supply and annealing stages the adsorbed $\mathrm{C}_{2} \mathrm{H}_{2}$ molecules are found to perform random walks on the surface of the cluster (see Movie S1 of trajectory C in the Supporting Information), and undergo chemical reactions that result in the oligomerization of small hydrocarbon species, as can be seen in the snapshot geometries of the ten trajectories after 30 ps and 110 ps simulation time in Figure 2 (also see the movie S2 of trajectory A of this 80 ps annealing stage in the Supporting Information). 

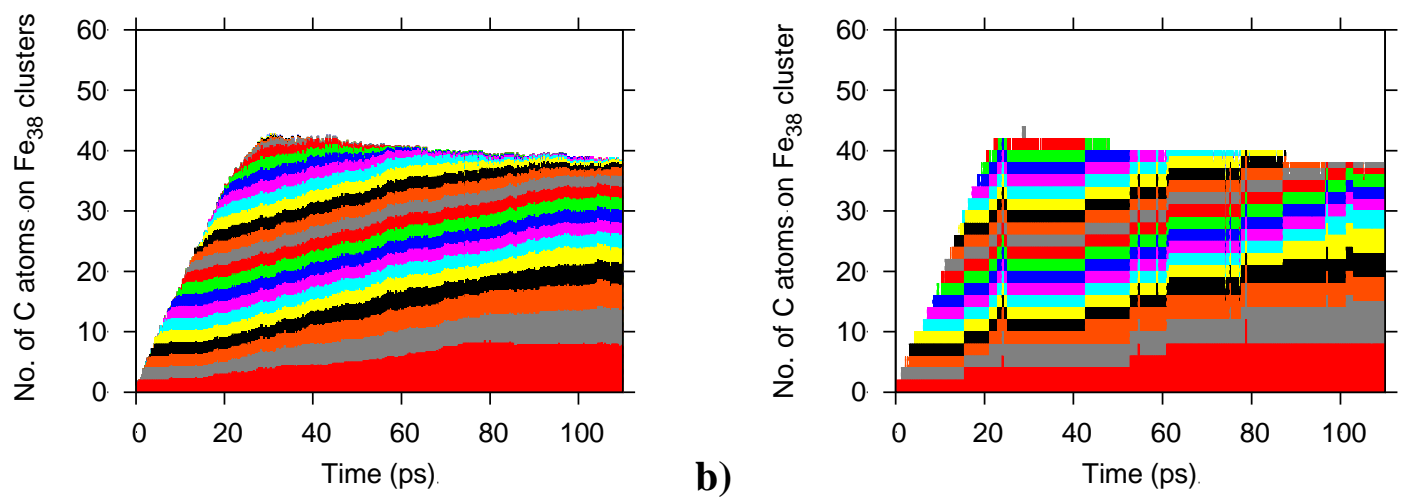

a)

b)

Figure 3 - Size evolution of hydrocarbon clusters $\mathrm{C}_{x} \mathrm{H}_{y}$ adsorbed on the $\mathrm{Fe}_{38}$ particle over the entire simulation time. The number $x$ of carbon atoms for each cluster was recorded at time intervals of $0.2 \mathrm{ps}$ and the size of the clusters present on the nanoparticle are displayed as vertical bars arranged by size from bottom (largest cluster, red) to top (smallest cluster). Panel a) shows the average over the ten trajectories, b) shows trajectory $A$ as a representative example.

a)

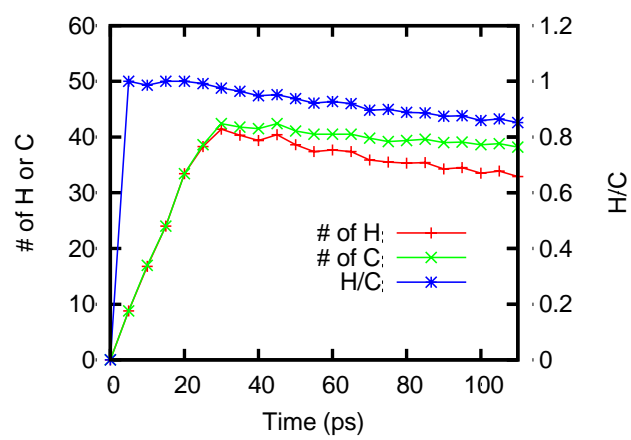

b)

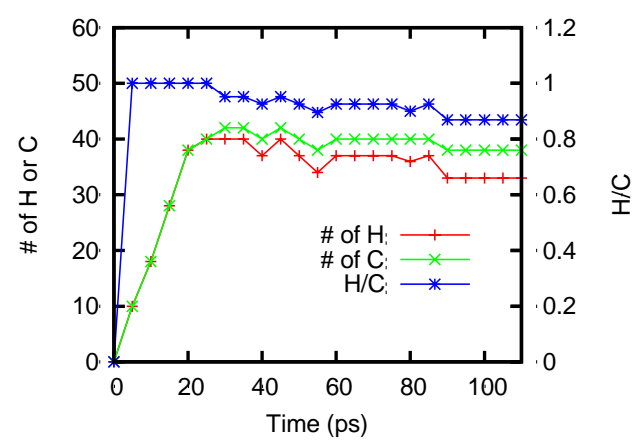

Figure 4 - Overall number of hydrogens and carbon atoms, and overall $\mathrm{H} / \mathrm{C} y: x$ ratio of individual hydrocarbon clusters $\mathrm{C}_{x} \mathrm{H}_{y}$ adsorbed on the $\mathrm{Fe}_{38}$ particle over the $110 \mathrm{ps}$ simulation time. The number of $\mathrm{H}$ and $\mathrm{C}$ atoms and the $\mathrm{H} / \mathrm{C}$ ratio were recorded at time intervals of 5 ps. Panel a) shows the average over the ten trajectories, b) shows trajectory $A$ as a representative example. 


\subsection{Early-stage hydrocarbon cluster evolution}

It is convenient to discuss the early-stage evolution of the metal-adsorbed hydrocarbon species in terms of their $\mathrm{C}_{x} \mathrm{H}_{y}$ composition, analogous to the hydrocarbon growth analysis we employed earlier in simulations of fullerene [86] and PAH [87] formation during benzene combustion. Since $x$ corresponds to the number of carbon atoms present in individual hydrocarbon species, this quantity represents the "size" of the carbon-containing clusters from which a nascent CNT might grow. The time evolution of $x$ is shown in Figure 3 for $110 \mathrm{ps}$, including $30 \mathrm{ps}$ initial supply and $80 \mathrm{ps}$ initial annealing periods, using the average of $x$ over the ten trajectories (Figure 3a) and the value of $x$ in the individual trajectory A as a representative example (Figure 3b). As mentioned earlier, the theoretical coverage of 60 carbon atoms at $30 \mathrm{ps,} \mathrm{representing} \mathrm{a} \mathrm{100 \%} \mathrm{chemisorption,} \mathrm{is} \mathrm{not} \mathrm{reached} \mathrm{during} \mathrm{the} \mathrm{initial}$ supply simulations. This is because incoming acetylene molecules are occasionally deflected from the metal particle due to the presence of already adsorbed hydrocarbons, with increasing frequency as the metal particles become gradually covered. This is in sharp contrast to the shooting of $C_{2}$, where the chemisorption is virtually $100 \%$ [46], since $C_{2}$ molecules are diradicals and can react with other carbon species present on the metal particle. Nevertheless, it is apparent from Figure 3 that with increasing time, smaller fragments are gradually consumed by larger clusters and seemingly "disappear" from the graph as the larger clusters increase in size; this was also observed in our previous study of fullerene formation in benzene combustion [86]. However, the hydrocarbon growth rate of this study is much less than for benzene combustion due to the fact that a) the presence of the metal catalyst reduces the hydrocarbon diffusion rate, and b) hydrogen atoms are not removed in the initial 
supply and annealing stages. The existence of a maximum in $x$ around 30 ps indicates that a small number of carbon atoms were lost from the metal cluster during the initial annealing stage, due to the dissociation of C2 hydrocarbon species (evident in Figure 3b for individual trajectory A).

We now address the decomposition of the acetylene feedstock on the iron nanoparticle during the initial supply and annealing stages. Figure 4 displays the total number of hydrogen $(y)$ and carbon atoms $(x)$ as well as the $\mathrm{H} / \mathrm{C}$ ratio $(y / x)$ for the average over ten trajectories (Figure 4a) and the individual trajectory A (Figure 4b). The H/C ratio is a particularly useful indicator of the fate of the hydrogens during the cluster growth. Beginning with a $1: 1$ ratio in $\mathrm{C}_{2} \mathrm{H}_{2}$, the $\mathrm{H} / \mathrm{C}$ ratio will eventually reach a value of zero in the case of a CNT, with intermediate values in between. We note that over the course of the 110 ps simulation time, the overall $\mathrm{H} / \mathrm{C}$ ratio only slightly decreases to an average value of 0.86. The slow decomposition of the hydrocarbons can be attributed to the difficulty of $\mathrm{C}-\mathrm{H}$ bond cleavage on the simulated time scale, and is consistent with the observed low cross-section for the formation and elimination of $\mathrm{H}_{2}$, which would be the only route for an irreversible reduction of the hydrogen concentration on the metal surface. In fact, $\mathrm{H}_{2}$ formation was rarely found in our simulations and only abundant in supplementary simulations with 20 hydrogen atoms supplied on $\mathrm{Fe}_{38}$ on the picosecond timescale. Instead, atomic hydrogen adsorbed on the metal cluster easily reacts with adsorbed hydrocarbon species, causing the appearance of little change in the $\mathrm{H} / \mathrm{C}$ ratio when viewed independently from hydrogen movement. 


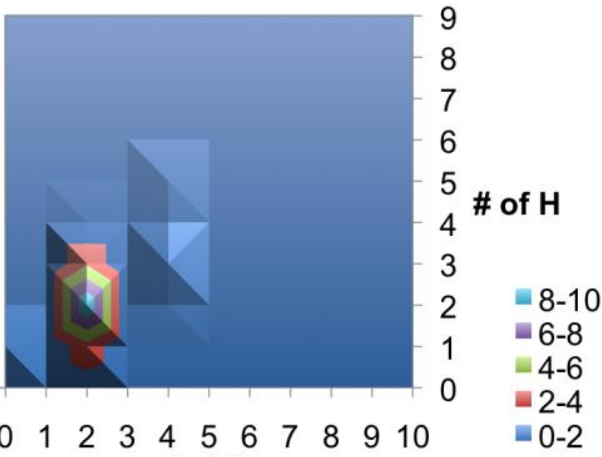

a)

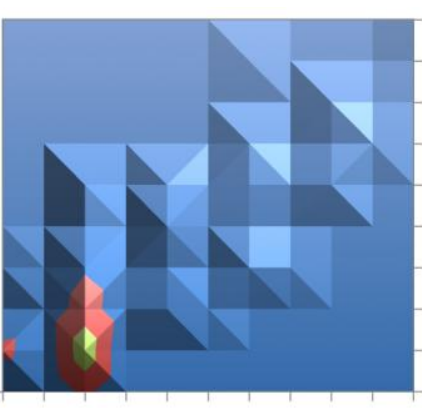

$\begin{array}{lllllllllll}0 & 1 & 2 & 3 & 4 & 5 & 6 & 7 & 8 & 9 & 10\end{array}$

\# of C

$-2-3$

$\pm 1-2$

b)

Figure 5 - Abundance of the hydrocarbon $\mathrm{C}_{x} \mathrm{H}_{y}$ species on the $\mathrm{Fe}_{38}$ cluster, a) after $30 \mathrm{ps}$ supply simulation, b) after 110 ps at the end of the annealing simulation, averaged over ten trajectories. Abundance (average number of species) is measured on a color scale corresponding to ranges specified in the legend. A shadow effect was used to enhance the visibility of peak heights.

However, hydrogen atoms do move in the course of our simulations, as shown in Figure $5 \mathrm{a}$ and $5 \mathrm{~b}$ after $30 \mathrm{ps}$ and $110 \mathrm{ps}$, respectively (alternative graphical renderings are shown in the Supplementary Information in Figure S1). Here we plot the average abundance of $\mathrm{C}_{x} \mathrm{H}_{y}$ species on a 2D grid spanned by the $x$ and $y$ axes. We will discuss initial supply and annealing stages separately in the following two paragraphs.

\subsubsection{Initial $\mathrm{C}_{2} \mathrm{H}_{2}$ supply stage}

At the end of the 30 ps initial supply stage, there are only three major species present on the $\mathrm{Fe}_{38}$ particle: $\mathrm{C}_{2} \mathrm{H}_{2}, \mathrm{C}_{2} \mathrm{H}_{3}$, and $\mathrm{C}_{2} \mathrm{H}$, in order from highest to lowest abundance. $\mathrm{C}_{2}$ is the $4^{\text {th }}$ most abundant species, but it appears by about one order of magnitude less than the aforementioned three species. Only a few dimerization reactions have occurred, yielding $\mathrm{C}_{4} \mathrm{H}_{\mathrm{y}}$ species, mostly with $y=3$. We find that the following reactions occurred most often:

$$
\mathrm{C}_{2} \mathrm{H}_{2} \text { (ads) } \square \mathrm{C}_{2} \mathrm{H}(\text { ads })+\mathrm{H}(\text { ads })
$$




$$
\begin{aligned}
& 2 \mathrm{C}_{2} \mathrm{H}_{2} \text { (ads) } \square \mathrm{C}_{2} \mathrm{H}(\text { ads })+\mathrm{C}_{2} \mathrm{H}_{3} \text { (ads) } \\
& \mathrm{C}_{2} \mathrm{H}_{2} \text { (ads) }+\mathrm{C}_{2} \mathrm{H} \text { (ads) } \square \mathrm{C}_{4} \mathrm{H}_{3} \text { (ads) }
\end{aligned}
$$

Reaction (1) constitutes a transfer of hydrogen to the metal particle, reaction (2) is a hydrogen disproportionation, and reaction (3) is the carbon-carbon bond formation between a $\mathrm{C}_{2} \mathrm{H}$ radical and an acetylene molecule. Reactions (1) and (2) occur most often. While straightforward acetylene dimerization is a rare event, the more reactive $\mathrm{C}_{2} \mathrm{H}$ radical species initiate oligomerization reactions among the adsorbed $\mathrm{C}_{2} \mathrm{H}_{y}(y=1,2,3)$ molecules, producing many $\mathrm{C}_{4} \mathrm{H}_{\mathrm{y}}$ species via reaction (3). There were five trajectories where one $\mathrm{C}-\mathrm{C}$ bond formation took place (trajectories B, D, E, F, and H), three trajectories where two C-C bonds were formed (trajectories A, G, and I), and even one trajectory producing three $\mathrm{C}_{4} \mathrm{H}_{\mathrm{x}}$ oligomers (trajectory $\mathrm{C}$ ). The newly created $\mathrm{C}_{4} \mathrm{H}_{\mathrm{y}}$ species are highlighted in Figure 2 a) with purple color. Other reactions, such as the dimerization of $\mathrm{C}_{2} \mathrm{H}$, occur less frequently.

\subsubsection{Initial annealing stage}

The most pronounced feature of the subsequent 80 ps annealing simulations was the increase in the size of the adsorbed $\mathrm{C}_{x} \mathrm{H}_{y}$ clusters, as is evident from Figures 2, 3, and 5. The largest hydrocarbon species formed was $\mathrm{C}_{14} \mathrm{H}_{13}$ in trajectory E. Second, we note in Figure $5 \mathrm{~b}$ that further hydrogen disproportionation has occurred: the $\mathrm{C}_{x} \mathrm{H}_{y}$ species are now scattered along the diagonal of the 2D plots, indicating hydrogen transfers away from hydrogen-poor clusters and towards hydrogen-rich clusters. Such disproportionation had not been observed in earlier fullerene formation simulations, since there we had removed hydrogen gradually to simulate the oxidation reactions occurring in combustion [86]. Interestingly, the most abundant hydrocarbon species after 110 ps simulation time is $\mathrm{C}_{2} \mathrm{H}$. We have confirmed that 
individual $\mathrm{C}_{2} \mathrm{H}$ species are continually consumed and regenerated, adopting the role of a "dissipative" organocatalyst [88] during hydrocarbon formation and carbon segregation, in the sense of Prigogine's nonequilibrium "dissipative structures" [89]. Although there is no direct experimental evidence, the formation of the $\mathrm{C}_{2} \mathrm{H}$ radical is the energetically most favorable pathway for acetylene incorporation, and it is argued as the most important pathway that makes carbon incorporation from acetylene more efficient than from the other C2 carbon source molecules [30], based on the HACA mechanism. Moreover, for the first time in the simulations, we observe the formation of five- (trajectories A, E, and I) or six-membered hydrocarbon rings (Trajectory F) during oligomerization and cross-linking, clearly visible in the structures shown in Figure $2 b$. To distinguish the newly formed clusters from the $\mathrm{C}_{4} \mathrm{H}_{y}$ that were created during the earlier carbon supply stage, we highlighted them with blue color.

a)

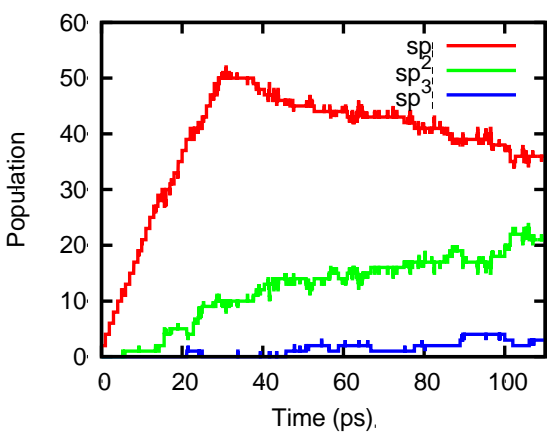

b)

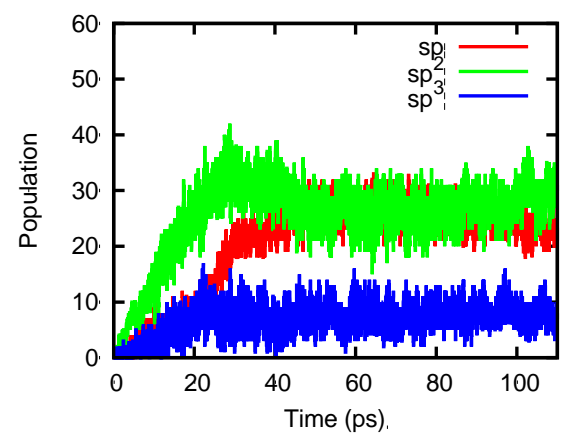

Figure 6 - Carbon hybridization count analysis (red: sp, green: $\mathrm{sp}^{2}$, and blue: $\mathrm{sp}^{3}$ type carbons) as function of time for trajectory A. a) excluding counting Fe-C bonds; b) including $\mathrm{Fe}-\mathrm{C}$ bonds. The threshold values of $\mathrm{C}-\mathrm{C}$ and $\mathrm{C}-\mathrm{Fe}$ bonds were 2.0 and 2.5 Å, respectively.

\subsection{Early-stage carbon ring network}


The formation of a condensed ring network will be discussed by the change in hybridization from $\mathrm{sp}$ to $\mathrm{sp}^{2}$ carbon (as counted by the number of bond partners), an analysis technique we had employed before in references [86, 87, 90]. However, in systems containing $\mathrm{C}$ and $\mathrm{H}$, $\mathrm{sp}^{2}$ carbon does not necessarily indicate a carbon network. C-Fe bonds additionally complicate the situation in the present system. We use trajectory A as a representative example and show in Figure 6 the carbon hybridization count as a function of simulation time during the first $110 \mathrm{ps.}$ Other trajectories show similar features.

The hybridization type $\left(\mathrm{sp}, \mathrm{sp}^{2}, \mathrm{sp}^{3}\right)$ was estimated from the number of bond partners in snapshot geometries, where we included C-C and C-H bonds in Figure 6a and additionally also C-Fe bonds in Figure 6b. The applied threshold values for bond lengths were $1.5 \AA(\mathrm{C}-\mathrm{H}), 2.0 \AA(\mathrm{C}-\mathrm{C})$, and $2.5 \AA(\mathrm{C}-\mathrm{Fe})$ bonds. During the carbon supply simulation, the number of sp carbon increases in Figure 6a very quickly (red curve) and reaches a maximum at $30 \mathrm{ps}$, the end of supply simulation. This behavior reflects the fact that acetylene was gradually added up to this point. During the annealing from 30 ps to 110 $\mathrm{ps}$, the number of $\mathrm{sp}$ carbon atoms then decreased while the number of $\mathrm{sp}^{2}$ carbon atoms increased instead. The number of $\mathrm{sp}^{3}$ carbon atoms was negligible during the entire simulation. On the other hand, when Fe-C bonds are included in the determination of the carbon hybridization in Figure $6 \mathrm{~b}$, we find that both the numbers of $\mathrm{sp}$ and $\mathrm{sp}^{2}$ carbon atoms increased during the supply stage, consistent with the fact that the acetylene molecules adsorbed on the Fe cluster. At about $20 \mathrm{ps}$, we see an increase in the number of $\mathrm{sp}^{3}$ carbon atoms in Figure 6b, consistent with the increase of $\mathrm{sp}^{2}$ carbon atoms in Figure $6 \mathrm{a}$ at the same time. Note that the hybridization counts in Figure $6 \mathrm{~b}$ have a broader fluctuation as compared to the curves shown in Figure 6a, indicating frequent $\mathrm{Fe}-\mathrm{C}$ bond formation and 
breakage events.
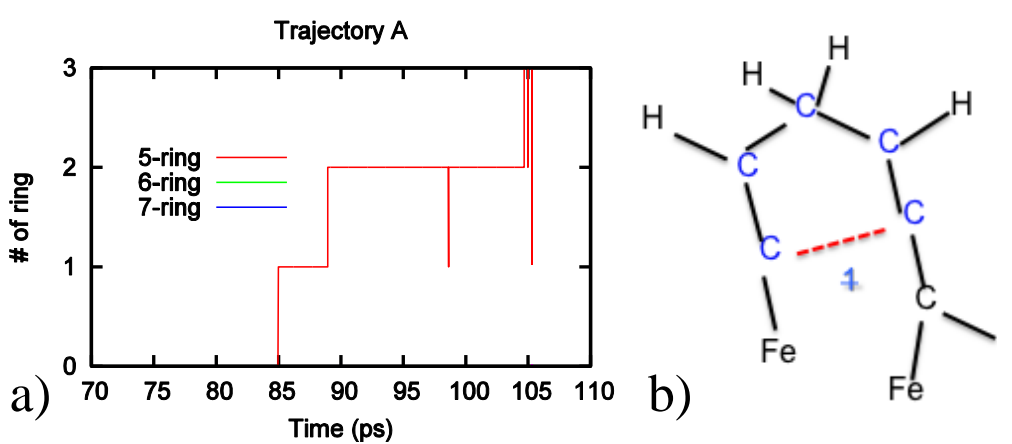

c )
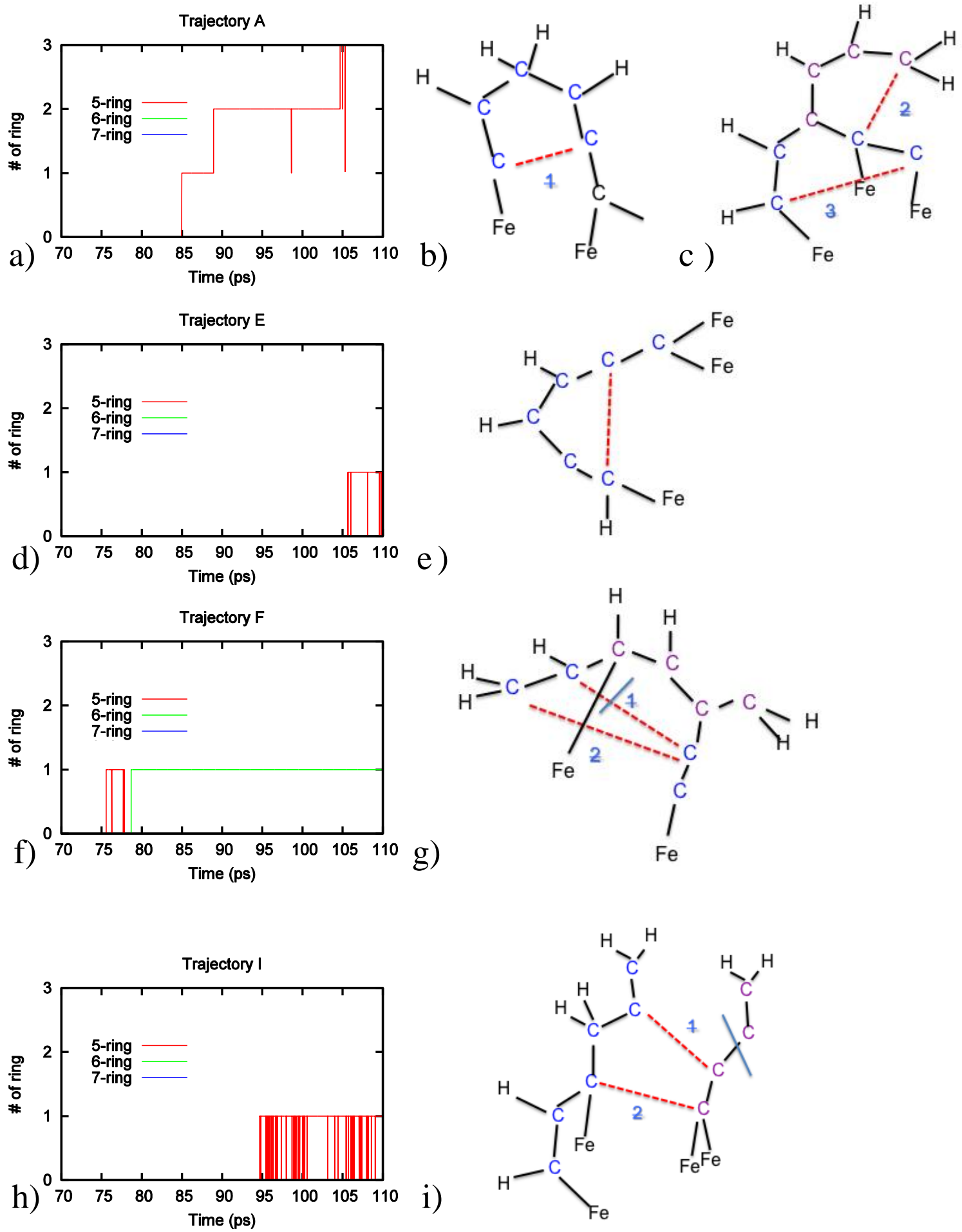

i)

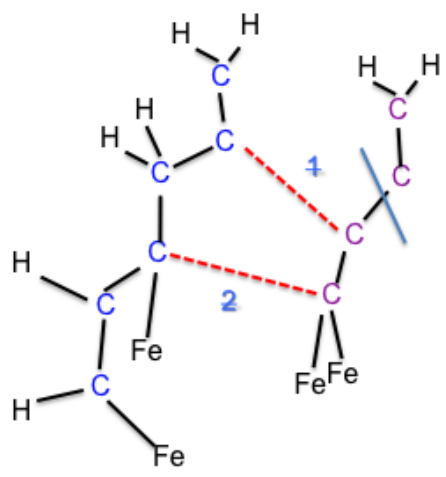

Figure 7 - Carbon ring count statistics as a function of simulation time, and schematic depictions of hexagon or pentagon formation processes from hydrocarbon chains on an iron cluster. Panels a,b,c) for trajectory A; d,e) for trajectory $E$; f,g) for trajectory $F$ and $\mathbf{h , i}$ ) for trajectory I. Red dashed lines and blue solid lines indicate newly formed and broken $\mathrm{C}-\mathrm{C}$ bonds. Numbers in the schemes indicate the reaction step sequence. 
Figure 7 depicts ring population statistics during the first 110 ps for selected trajectories, and shows schematically the ring formation mechanisms leading to the observed carbon rings. In the ring population plots of Figure $7 \mathrm{a}, \mathrm{d}, \mathrm{f}$, and $\mathrm{h}$, it is observed that rings are strikingly sparse in comparison to the ring counts of our previous simulations of cap nucleation on $\mathrm{Fe}_{38}$ [46]. In all trajectories up to $110 \mathrm{ps,} \mathrm{only} \mathrm{a} \mathrm{total} \mathrm{of} \mathrm{seven} \mathrm{rings} \mathrm{was} \mathrm{produced} \mathrm{(six} \mathrm{pentagons}$ and one hexagon), whereas in the case of $\mathrm{C}_{2}$ supply simulations after 80 ps [46], each trajectory had produced approximately one pentagon. Since the average H/C ratio is still high with 0.86 at the end of the 110 ps simulation time, we attribute the lower ring production rate to negative (inhibiting) effect of hydrogen for the condensation of carbon ring networks. A similar inhibiting effect had been observed in the case of benzene combustion [86, 87], where we resorted to randomly remove hydrogen atoms in the spirit of a hybrid Monte Carlo/MD scheme.

As can be seen in Figure 7, the first ring produced was always a pentagon, in striking similarity to our previous simulations of cap nucleation from $\mathrm{C}_{2}$ molecules on $\mathrm{Fe}_{38}$ [46], indicating that geometrical factors such as the proximity of second-nearest neighbors play a greater role in the "pentagon-first" mechanism as opposed to thermodynamic stability. While in the $\mathrm{C}_{2}$-on-Fe $\mathrm{Fe}_{38}$ simulation the "Y-junction" of C-C(C)-C type was the pivot of the pentagon formation, in the present acetylene simulation we find that a $\mathrm{C}-\mathrm{C}(\mathrm{H})-\mathrm{C}$ type Y-junction plays a similar role. Moreover, we note that $\mathrm{C}-\mathrm{C}$ bonds are preferably made with under-coordinated carbon atoms, i.e., short sp carbyne chains and/or carbon bound to $\mathrm{Fe}$ atoms. 


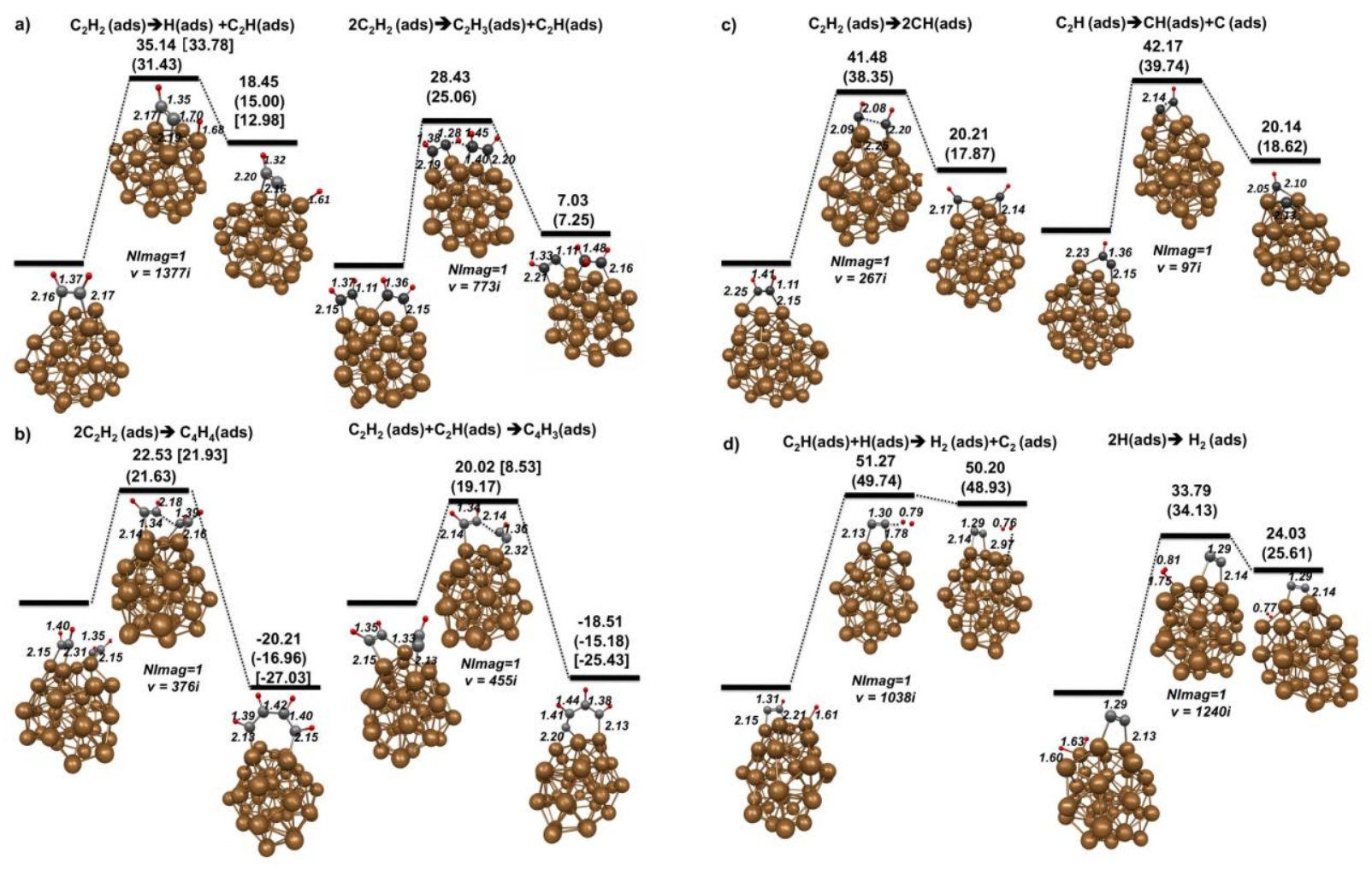

Figure 8 - The reaction energy profiles and optimized geometries of reactants, transition states (TS), and products of four types of key elementary reactions occurring during the QM/MD simulations. The four panels show: a) $\mathrm{H}$ transfer reactions; b) $\mathrm{CC}$ bond formation reactions; c) $\mathrm{CC}$ cleavage reactions; d) $\mathrm{H}_{2}$ formation reactions. In the case of TS, energies correspond to the forward direction barrier from the reactant, and NImag indicates the number of imaginary frequencies and its value in $\left(\mathrm{cm}^{-1}\right)$. In the case of products, energies relative to the reactants indicate exothermic (negative) or endothermic (positive) reaction energies. Plain values correspond to DFTB total energies, values in parentheses include the ZPE correction at the DFTB level, and values in square brackets were obtained at the PBE/DZP//DFTB level of theory without ZPE correction.

\subsection{Energy profiles for model chemical reactions during early-stage nucleation}

As model systems for elementary reaction steps during acetylene oligomerization and hydrogen elimination, we chose complexes with one and two $\mathrm{C}_{2} \mathrm{H}_{2}$ molecules on an $\mathrm{Fe}_{38}$ 
particle. The potential energy profiles were computed for the following four different kinds of elementary reactions, namely a) hydrogen transfer, b) CC bond formation, c) CC bond cleavage, and d) $\mathrm{H}_{2}$ formation. For each reaction, two representative events were selected from the QM/MD trajectories. Initial guesses for the transition state (TS) molecular geometries of these one-step reactions were first extracted from the trajectories. These structures were subjected to geometry optimization, followed by vibrational normal mode analysis (NMA) to verify that the optimized TS structure had only one imaginary vibrational mode. Starting from the TS, the corresponding reactants and products were then obtained by geometry optimization, and again followed by NMA to verify that these structures were minima on the potential energy surface. Schematic energy profiles and stationary points of the eight elementary reactions are shown in Figure 8, as well as their forward barriers, reaction energies, and imaginary frequencies of the TSs. For the definition of relative energies, we used the energy of the reactants as reference.

To verify the reliability of the DFTB reaction energetics, PBE/DZP single-point energy calculations at the DFTB optimized geometries were performed for the a) hydrogen transfer and b) CC bond formation reactions. We found that the PBE barrier heights agreed well with DFTB barriers within 2 to $4 \mathrm{kcal} / \mathrm{mol}$, while the reaction energies were more exothermic by up to $6 \mathrm{kcal} / \mathrm{mol}$. In the case of the $\mathrm{C}_{2} \mathrm{H}_{2}+\mathrm{C}_{2} \mathrm{H} \mathrm{CC}$ bond formation reaction, the difference was somewhat larger, the barrier and reaction energy being decreased by 12 $\mathrm{kcal} / \mathrm{mol}$ and $7 \mathrm{kcal} / \mathrm{mol}$ in PBE calculations, respectively. Given the large variance of different DFT functionals, in particular for metallic systems, we found that the differences were certainly qualitatively in good agreement and even quantitatively acceptable, and that the DFTB method was able to describe the relevant chemical processes of this system. In 
the following discussion we will therefore focus on DFTB results only.

\subsubsection{Hydrogen transfer}

In our MD simulation, essentially two types of $\mathrm{H}$ transfer reactions from $\mathrm{C}_{2} \mathrm{H}_{2}$ were found, already mentioned in equations (1) and (2). Figure 8a shows the minimum energy reaction profiles for both pathways: the left profile in this panel is for the transfer of a hydrogen atom from acetylene to the iron particle corresponding to equation (1), while the right profile is that for the disproportionation mechanism leading to $\mathrm{C}_{2} \mathrm{H}$ and $\mathrm{C}_{2} \mathrm{H}_{3}$ corresponding to equation (2). As mentioned earlier, the hydrogen atoms of an $\mathrm{C}_{2} \mathrm{H}_{2}$ molecule adsorbed on the Fe particle form an angle of roughly $120^{\circ}$ with the $\mathrm{C}-\mathrm{C}$ bond and are pointing away from the iron nanoparticle. The distance between $\mathrm{Fe}$ and either carbon atom was about $2.16 \AA$, while the C-C bond length was elongated up to $1.37 \AA$. The forward barrier of the hydrogen transfer to the nanoparticle (left panel) was high with $35.1 \mathrm{kcal} / \mathrm{mol}$. In the TS structure, the length of the breaking $\mathrm{C}-\mathrm{H}$ bond was about $1.70 \AA$, which is $\sim 54 \%$ longer than the $\mathrm{C}-\mathrm{H}$ bond length in the reactant. In contrast, the length of the forming $\mathrm{H}-\mathrm{Fe}$ bond was also roughly $1.68 \AA$, which is only $4 \%$ longer than the $\mathrm{H}-\mathrm{Fe}$ bond in product (i.e., $1.61 \AA$ ). The transition state is therefore more similar to the product structure, consistent with the endothermicity of the reaction by $18.5 \mathrm{kcal} / \mathrm{mol}$. The forward barrier in the disproportionation mechanism, depicted in the right side of Figure $8 \mathrm{a}$, is lower in energy with $28.4 \mathrm{kcal} / \mathrm{mol}$ than the hydrogen transfer reaction and less endothermic with $\sim 7 \mathrm{kcal} / \mathrm{mol}$. This barrier should not be a serious obstacle in the present simulation at $1500 \mathrm{~K}$. These results confirm our observations from the QM/MD simulations that, due to the lower forward barrier and reduced endothermicity of the disproportionation mechanism as opposed to $\mathrm{H}$ transfer to the iron 
particle, most hydrogen atoms will involve in disproportionation reactions. If the hydrogen-rich, less strongly adsorbed hydrocarbon products are lost to the vacuum, the hydrogen disproportionation mechanism introduces an irreversible process. We note that, due to the classical Newtonian treatment of the nuclei in our QM/MD simulations, no effects of quantum tunneling are included. It can be expected that in reality, tunneling may enhance hydrogen transfer reaction rates on the order of several ten percent.

\subsubsection{CC bond formation}

In the QM/MD simulations, various $\mathrm{C}_{2} \mathrm{H}_{y}(y=1,2)$ oligmerization reactions were observed. Here we focus on two energetically favorable dimerization reactions as shown in Figure $8 \mathrm{~b}$ : dimerization of two $\mathrm{C}_{2} \mathrm{H}_{2}$ (left), and $\mathrm{CC}$ bond formation between $\mathrm{C}_{2} \mathrm{H}_{2}$ and a $\mathrm{C}_{2} \mathrm{H}$ radical (right). These two reactions show surprisingly similar features with forward barriers of about $21 \mathrm{kcal} / \mathrm{mol}$. In the reactants, for both TSs, the distances of the newly formed C-C bonds were close $(2.18 \AA$ vs. $2.14 \AA$ ). In the $\mathrm{C} 4$ products, the new C-C bonds were longer with $\sim 1.42 \AA$ than the terminal bonds with $\sim 1.39 \AA$, indicating a partial s-cis-1,3-butadiene-like electronic structure. Both oligmerization products are strongly exothermic with about $-19 \mathrm{kcal} / \mathrm{mol}$ reaction energies. For comparison, in vacuum, the dimerization barrier of $\mathrm{C}_{2} \mathrm{H}_{2}$ without $\mathrm{Fe}$ was higher by about $30 \mathrm{kcal} / \mathrm{mol}$ at the DFTB level, which indicates that $\mathrm{Fe}$ indeed catalyzes the dimerization of $\mathrm{C}_{2} \mathrm{H}_{2}$ during $\mathrm{CNT}$ growth. On the other hand, the barrier for the $\mathrm{C}_{2} \mathrm{H}_{2}+\mathrm{C}_{2} \mathrm{H}$ reaction was much lower in vacuum (9.98 $\mathrm{kcal} / \mathrm{mol}$ ). Apparently, adsorbed on an Fe particle, the reactive dangling bond of the $\mathrm{C}_{2} \mathrm{H}$ radical is somewhat passivated, leading to a higher reaction barrier for oligomerization comparable to that of the lowered barrier for $\mathrm{C}_{2} \mathrm{H}_{2}$ dimerization. This result is inline with 
our QM/MD simulations, in which we observed for the first 30 ps of carbon supply that in eight trajectories $(80 \%) \mathrm{C}_{2} \mathrm{H}_{2}$ formed $\mathrm{CC}$ bonds with $\mathrm{C}_{2} \mathrm{H}$, while $\mathrm{C}_{2} \mathrm{H}_{2}$ dimerization was observed only in two trajectories $(20 \%)$.

\subsubsection{CC bond cleavage}

In the MD simulation, we also occasionally observed $\mathrm{CC}$ bond cleavage. Here, we considered two archetypical cleavage reactions, namely

$$
\begin{aligned}
& \mathrm{C}_{2} \mathrm{H}_{2} \text { (ads) } \rightarrow 2 \mathrm{CH}(\text { ads }) \\
& \mathrm{C}_{2} \mathrm{H}(\text { ads }) \rightarrow \mathrm{CH}(\text { ads })+\mathrm{C}(\text { ads })
\end{aligned}
$$

Both reactions have high energy barriers of about $41 \mathrm{kcal} / \mathrm{mol}$ and are endothermic by about $20 \mathrm{kcal} / \mathrm{mol}$ (Figure 8c), therefore not favorable even at $1500 \mathrm{~K}$. Thus, in our QM/MD simulations, $\mathrm{CC}$ bond cleavage took place only in long hydrocarbon chains, instead of $\mathrm{C}_{2} \mathrm{H}_{y}$. This result suggests that the often proposed dissolution of atomic carbon into a metal carbide phase requires long time scales, and will be outcompeted by CC bond formation reactions if hydrocarbon fragments approach each other on the metal surface.

\subsection{4. $\mathrm{H}_{2}$ formation}

Two types of $\mathrm{H}_{2}$ formation reactions were investigated,

$$
\begin{aligned}
& \mathrm{C}_{2} \mathrm{H}(\text { ads })+\mathrm{H}(\text { ads }) \rightarrow \mathrm{H}_{2}(\mathrm{~g})+\mathrm{C}_{2} \text { (ads) } \\
& 2 \mathrm{H}(\text { ads }) \rightarrow \mathrm{H}_{2}(\mathrm{~g})
\end{aligned}
$$

As shown in Figure 8d, reaction (6) has a high energy barrier of about $51 \mathrm{kcal} / \mathrm{mol}$ and an endothermicity of $50 \mathrm{kcal} / \mathrm{mol}$. Following the Hammond postulate [91], the TS is extremely "late" in character, and we find it exceedingly difficult to form $\mathrm{H}_{2}$ molecules from 
Fe-adsorbed $\mathrm{H}$ and $\mathrm{C}_{2} \mathrm{H}$. Reaction (7) has a lower barrier, about $34 \mathrm{kcal} / \mathrm{mol}$, but is still endothermic with $24 \mathrm{kcal} / \mathrm{mol}$. Moreover, in QM/MD simulations it was rarely possible for two $\mathrm{H}$ atoms to be adsorbed on the same Fe cluster simultaneously, since the small $\mathrm{Fe}_{38}$ cluster was crowded with adsorbed hydrocarbon species. Thus, within 80 ps of annealing simulations, no $\mathrm{H}_{2}$ molecule was observed at all. If the surface area of the nanoparticle is larger, the free energy gain by producing $\mathrm{H}(\mathrm{ads})$ would be greater due to the entropy gain, especially at higher temperature. However, it is unclear by how much the barriers of hydrogen transfer reactions would decrease due to this entropic contribution, and numerical simulations on larger iron nanoparticles are exceeding our current computer resources. We can conclude that $\mathrm{H}_{2}$ formation and elimination is a rare event in our simulations, given the present simulation reaction conditions.

\subsection{Secondary supply and annealing simulations}

Initial supply and annealing simulations up to $110 \mathrm{ps}$ did not allow a) the iron cluster to reach a sufficiently high carbon concentration, and b) hydrogen to deplete from the system; as a result, ring formation and $\mathrm{sp}^{2}$ carbon network formation had been significantly inhibited. Therefore, we implemented a secondary acetylene supply stage commencing at $110 \mathrm{ps}$ and conducted until at least 60 carbon atoms were present on the cluster. In this secondary supply, we paired each added $\mathrm{C}_{2} \mathrm{H}_{2}$ with random removal of two hydrogen atoms from the combined system. Such hydrogen removal is rooted in the spirit of a hybrid Monte Carlo/MD scheme, and allows to overcome the large barriers associated with the $\mathrm{H}_{2}$ elimination step discussed in the previous section. The same technique had been 
successfully employed earlier in our nonequilibrium MD studies of SWCNT formation from SiC crystals [69] and in the study of benzene combustion [86, 87]. The ten final cluster geometries after secondary supply, ranging in duration from 40 to $75 \mathrm{ps,}$, are depicted in the Supporting Information in Figure S2a.

a)
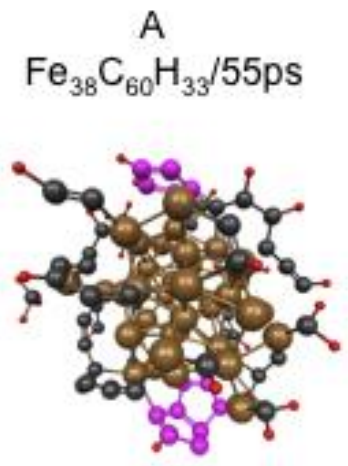

A2

$\mathrm{Fe}_{38} \mathrm{C}_{60} \mathrm{H}_{33} / 515 \mathrm{ps}$

b)

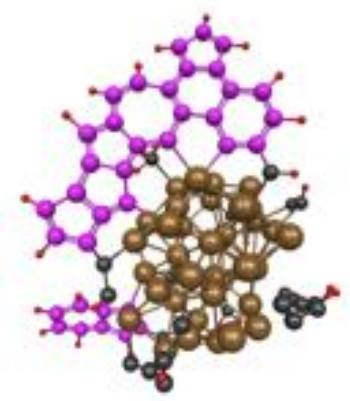

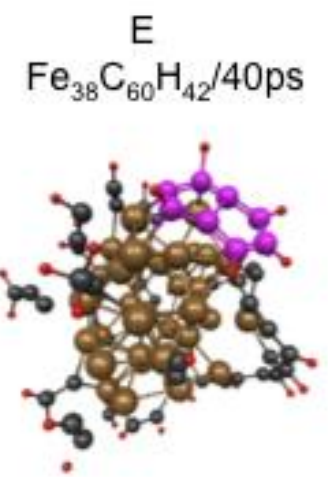

E2

$\mathrm{Fe}_{38} \mathrm{C}_{60} \mathrm{H}_{42} / 500 \mathrm{ps}$

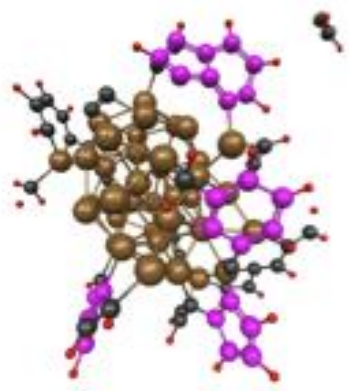

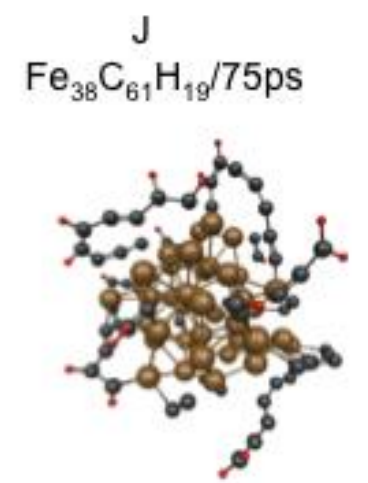

$\mathrm{Fe}_{38} \mathrm{C}_{61} \mathrm{H}_{19} / 535 \mathrm{ps}$

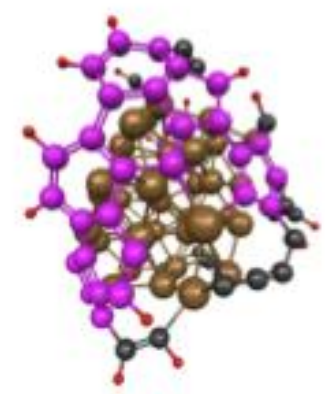

Figure 9 - Snapshots of trajectories A (standing-wall structure), E (fragments), and J (cap-like structure). a) at the end of 40-75 ps secondary carbon supply simulations when $\sim 60$ carbon density is reached. $b$ ) at the end of $350 \mathrm{ps}$ secondary annealing simulations. Gray, brown, and red spheres are carbon, iron, and hydrogen. The purple spheres highlight the formed ring by carbon. Total time is the sum of the first stage $30 \mathrm{ps}$ carbon supply, 80 ps annealing, 40-75 ps secondary carbon supply, and 350 ps secondary annealing simulations. 
The number of hydrogen atoms present in the system after the secondary supply/H removal simulations ranged from 19 (trajectory $\mathrm{J}$, at $185 \mathrm{ps}$ ) to 44 (trajectory $\mathrm{H}$, at $165 \mathrm{ps),}$ covering an $\mathrm{H} / \mathrm{C}$ ratio range from roughly 0.3 to 0.7 . From each of these ten structures A-J, we created three replicas and conducted secondary annealing simulations of $350 \mathrm{ps.} \mathrm{The}$ trajectories of this secondary annealing stage are labeled by numbers 1 to 3 added to the original alphabetic trajectory label (e.g., A1, A2, and A3 for trajectory A; see Figure 1). Upon analyzing the trajectories, we found that the $\mathrm{H} / \mathrm{C}$ ratio has a profound effect on the structures formed during annealing as previously in simulations of benzene combustion [87]: systems with lower $\mathrm{H}$ content (low $\mathrm{H} / \mathrm{C}$ ratio) will produce large, polycondensated PAHs or cap fragments (as seen in trajectory J1 in Figure 9), while those with higher H content (higher $\mathrm{H} / \mathrm{C}$ ratio) are not capable of large-area carbon network growth, and will produce isolated islands of smaller PAH fragments (as in trajectories A2 and E2 in Figure 9). The final geometry snapshots of all thirty trajectories, representing the state of the systems after more than $0.5 \mathrm{~ns}$ from initial acetylene supply, are shown in the Supporting Information in Figure S2b. Thus, our QM/MD simulations predict that SWCNT nucleation strongly depends on the amount of hydrogen present during the early stages of hydrocarbon adsorption and conversion. 


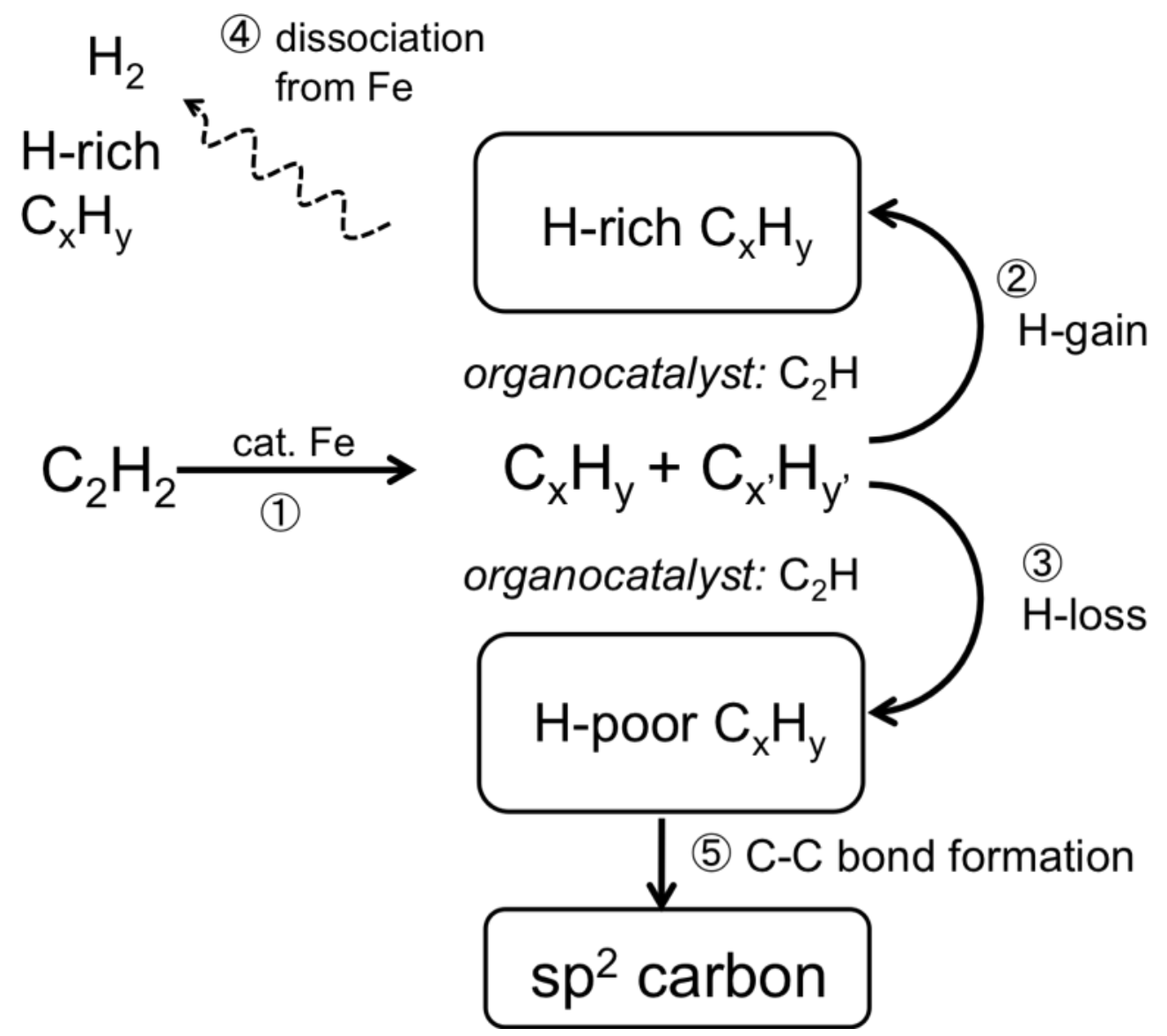

Figure 10 - Schematic representation of the initial chemical reactions of acetylene on an iron nanoparticle prior to cap formation, according to nonequilibrium QM/MD simulations.

\subsection{Discussions}

The presented QM/MD simulations have demonstrated that the presence of hydrogen has a significant inhibiting effect on $\mathrm{sp}^{2}$ carbon ring network formation, as we have previously reported for the fullerene formation mechanism in benzene combustion [86, 87, 90]. This effect is well known in the fullerene synthesis community [92, 93]: although hydrogen effectively inhibits fullerene formation, it promotes open-ended nanotube growth with defect-free hexagonal networks. Since molecular $\mathrm{H}_{2}$ formation and elimination was also associated with high energy barriers and never observed in our QM/MD simulations, we 
observe a tendency towards disproportionation in the early-stage supply and annealing simulations: where hydrogen-rich hydrocarbon species become hydrogen-richer and later dissociate from the metal particle as volatile organic species, less hydrogen-rich species become further hydrogen-depleted, presumably forming SWCNT nuclei at a later stage (see Figure 10). The situation is reminiscent of the well-established disproportionation of hydrocarbon species during combustion synthesis of PAHs and fullerenes [84]. This key finding of our study introduces a novel route to hydrogen loss during SWCNT nucleation, and highlights the central role of hydrogen in the SWCNT nucleation stage. If two hydrocarbon species meet on the metal surface, the low barriers for $\mathrm{CC}$ bond formation will favor immediately oligomerization reactions, producing longer $\mathrm{C}_{x} \mathrm{H}_{y}$ species that only get gradually hydrogen depleted or enriched in disproportionation reactions. This view is consistent with the detection of volatile organic compounds (VOCs) and/or polycyclic aromatic hydrocarbon species (PAHs) as common byproducts in CCVD SWCNT synthesis $[22,42,43]$.

Our QM/MD simulations and analysis of $\mathrm{C}_{x} \mathrm{H}_{y}$ surface species (Figures 4 and 5) indicated the surprising, constantly high relative concentration of the $\mathrm{C}_{2} \mathrm{H}$ species. Since barriers and reaction energies on the iron cluster for $\mathrm{C}-\mathrm{C}$ bond formation reactions between two acetylene and $\mathrm{C}_{2} \mathrm{H}_{2}+\mathrm{C}_{2} \mathrm{H}$ are rather similar, we conclude that its role is the formation of Y-junctions and the removal/transport of hydrogen. It seems to be constantly consumed and generated, enhancing other chemical reactions, and thus one might wish to call it a "dissipative organocatalyst", which has never been discussed before in the context of SWCNT growth mechanisms. However, its important role for hydrogen abstraction had already been implicated in our recent simulation of catalyst-free SWCNT growth from 
organic templates $[94,95]$, and hydrogen abstraction had been experimentally verified in a recent study by Itami and coworkers [96].

The implications of the simulation results on the VLS mechanism are as follows. For stage 1 , we suggest that the role of $\mathrm{C}_{2} \mathrm{H}$ should be studied by experimentalists in greater detail. For stage 2, we did not observe the dissolution of carbon into the metal particle. Neither did we observe carbide formation in our previous, carbon-only cap nucleation simulations [46]. The presence of the $\mathrm{C}-\mathrm{H}$ bond increases the time required for the formation of atomic carbon, required for carbide formation. If other active hydrocarbon species are present on the metal particle surface, we find that rapid oligomerization dominates, leading to hydrocarbon chains and eventually carbon pentagons and other rings. Thus, the hydrocarbon feeding rate is an important factor for the processes occurring on the catalyst surface.

Regarding the cap nucleation mechanism of stage 3, we find evidence that the high temperature intermediate polyyne cross-linking mechanism suggested by Eres et al. seems reasonable, albeit oversimplified. In our simulations, we have found large numbers of various hydrocarbon chains (in addition to polyyne-like chains) that can cross-link once hydrogen is removed from the system. Thus, it seems entirely possible that, depending on the hydrocarbon feeding rate, graphene-like wall or ring structures can be formed that only later coalesce to form the well known cap structure of a SWCNT. The route of SWCNT nucleation should strongly depend on the amount of hydrogen present in the nascent carbon network. 


\section{Summary and Conclusions}

We report the first direct nonequilibrium molecular dynamics (MD) simulations of acetylene CCVD SWCNT synthesis on an iron nanoparticle using a quantum chemical potential. In these reactive QM/MD simulations and energetic studies of model reactions, we were able to make the following observations concerning elementary chemical reactions that occur during single wall carbon nanotube cap nucleation:

1. Acetylene adsorbs easily on the catalyst surface, showing high surface mobility of the resulting $\mathrm{C}_{2} \mathrm{H}_{2}$ (ads) species (Figure 10 , reaction (1)).

2. We find no evidence for metal carbide formation in over $0.5 \mathrm{~ns}$ simulations.

3. Instead of the expected molecular $\mathrm{H}_{2}$ elimination, our simulations show that $\mathrm{C}_{x} \mathrm{H}_{y}$ species disproportionate over time into hydrogen-depleted and hydrogen-enriched hydrocarbon species (Figure 10, reactions (2) and (3), respectively). The former are eventually consumed by the growing SWCNT structure, while the latter dissociate as volatile organic species, consistent with experimental observations [22, 42, 43]

(Figure 10, reaction (4)). Such disproportionation is similar to processes occurring in oxygen-lean combustion of hydrocarbons [97].

4. $\mathrm{CC}$ bond formations (Figure 10, reaction (5) occur faster than $\mathrm{CC}$ bond cleavage or hydrogen transfer reactions, as demonstrated in the increasing carbon cluster size during QM/MD simulations (Figures 3 and 5), consistent with their lower forward reaction barriers and exothermic reaction energy (Figure 8).

5. Crosslinking between hydrocarbon oligomer chains may occur either via all-carbon "Y-junctions" of C-C(C)-C type as reported in our previous simulations of carbon cap 
nucleation on an iron particle [46], or hydrogen may take the role of one arm of the pivot carbon atom in $\mathrm{C}-\mathrm{C}(\mathrm{H})-\mathrm{C}$ type $\mathrm{Y}$-junctions.

6. The radical $\mathrm{C}_{2} \mathrm{H}(\mathrm{ads})$ species is the relatively most abundant species on the metal particle. Its reactivity is somewhat lower when adsorption on the metal particle than in the gas phase, nevertheless we find that this species is involved in a majority of elementary chemical reactions in the system $(\mathrm{CC}$ bond formation and $\mathrm{H}$ transfer reactions). Since this species is continuously consumed and regenerated during its participation in the disproportionation and carbon cluster growth mechanisms including the formation of carbyne $\mathrm{Y}$ junctions, we label it an example of a "dissipative organocatalyst." The situation is reminiscent of the well-established HACA growth mechanism of PAH formation in oxygen-lean combustion experiments, which also assumes the existence of radicals for hydrogen abstraction prior to acetylene addition $[51,52]$.

7. Consistent with experimental results [92], the presented simulations confirm the inhibiting role of hydrogen for carbon network growth.

8. According to our simulations, cap formation is not a necessary condition for SWCNT nucleation as often claimed in the literature [33]; depending on the feedstock pressure, large hydrocarbon clusters can grow before hydrogen abstractions allow the formation of a carbon-only tubular structure.

The findings of this study have direct implications on future experimental investigations. First, the impact of hydrogen content on elementary, combustion-like chemical reactions needs to be taken into consideration in SWCNT CCVD synthesis. Second, the role of $\mathrm{C}_{2} \mathrm{H}$ as a "dissipative organocatalyst" for hydrogen abstraction reactions needs to be studied. 
Lastly, new experiments are needed to reexamine the prevalent SWCNT cap nucleation and metal carbide formation stages of the VLS mechanism, since the results of this theoretical study in agreement with other experimental work do not support them.

Acknowledgements. This work was in part supported by CREST (Core Research for Evolutional Science and Technology) grants in the areas of 1) High Performance Computing for Multiscale and Multiphysics Phenomena and 2) of Synthesis and Novel Functions of Soft $\pi$-materials from JST. Y.W. acknowledges the support of the National Youth Fund (No. 21203174). X.G. acknowledges support by MOST 973 program of China (2012CB934001). The work at Oak Ridge National Laboratory (G.E.) was sponsored by the Materials Sciences and Engineering Division, Office of Basic Energy Sciences, U.S. Department of Energy. The simulations were performed in part using a generous computer time allocation at the Research Center for Computational Science (RCCS), Institute for Molecular Science (IMS), Okazaki. 


\section{References}

[1] Iijima S. Helical microtubules of graphitic carbon. Nature. 1991;354:56-8.

[2] Iijima S. Single-shell carbon nanotubes of 1-nm diameter. Nature. 1993;363:603-5. [3] Bethune DS, Kiang CH, DeVries MS, Gorman G, Savoy R, Beyers R. Cobalt-catalysed growth of carbon nanotubes with single-atomic-layer wall. Nature. 1993;363:605-7.

[4] Saito R, Dresselhaus MS, Dresselhaus G. Physical Properties of Carbon Nanotubes. London: Imperial College Press; 1998.

[5] Tasis D, Tagmatarchis N, Bianco A, Prato M. Chemistry of Carbon Nanotubes. Chem Rev. 2006;106:1105-36.

[6] De Volder MF, Tawfick SH, Baughman RH, Hart AJ. Carbon nanotubes: present and future commercial applications. Science. 2013;339(6119):535-9.

[7] Yasuda S, Futaba DN, Yamada T, Satou J, Shibuya A, Takai H, et al. Improved and Large Area Single-Walled Carbon Nanotube Forest Growth by Controlling the Gas Flow Direction. ACS Nano. 2009;3:4164-70.

[8] Homma Y, Liu H, Takagi D, Kobayashi Y. Single-walled carbon nanotube growth with non-iron-group "catalysts" by chemical vapor deposition. Nano Res. 2009;2(10):793-9.

[9] Journet C, Maser WK, Bernier P, Loiseau A, Lamy de la Chapelle M, Lefrant S, et al. Large-scale production of single-walled carbon nanotubes by the electric-arc technique. Nature. 1997;388:756-8.

[10] Guo T, Nikolaev P, Thess A, Colbert DT, Smalley RE. Catalytic growth of single-walled carbon nanotubes by laser vaporization. Chem Phys Lett. 1995;243:49-54.

[11] Thess A, Lee R, Nikolaev P, Dai H, Petit P, Robert J, et al. Crystalline Ropes of Metallic Carbon Nanotubes. Science. 1996;273:483-7.

[12] Nikolaev P, Bronikowski MJ, Bradley RK, Rohmund F, Colbert DT, Smith KA, et al. Gas-phase catalytic growth of single-walled carbon nanotubes from carbon monoxide. Chem Phys Lett. 1999;313:91-7.

[13] Cheng HM, Li F, Sun X, Brown SDM, Pimenta MA, Marucci A, et al. Bulk morphology and diameter distribution of single-walled carbon nanotubes synthesized by catalytic decomposition of hydrocarbons. Chem Phys Lett. 1998;289(5-6):602-10.

[14] Flahaut E, Govindaraj A, Peigney A, Laurent C, Rousset A, Rao CNR. Synthesis of single-walled carbon nanotubes using binary $\mathrm{Fe}, \mathrm{Co}, \mathrm{Ni} /$ alloy nanoparticles prepared in situ by the reduction of oxide solid solutions. Chem Phys Lett. 1999;300:236-42.

[15] Zhu Z, Jiang H, Susi T, Nasibulin AG, Kauppinen EI. The Use of NH3 to Promote the Production of Large-Diameter Single-Walled Carbon Nanotubes with a Narrow $(\mathrm{n}, \mathrm{m})$ Distribution. J Am Chem Soc. 2011;133:1224-7. 
[16] Ago H, Uehara N, Yoshihara N, Tsuji M, Yumura M, Tomonaga N, et al. Gas analysis of the CVD process for high yield growth of carbon nanotubes over metal-supported catalysts. Carbon. 2006;44:2912-8.

[17] Mora E, Pigos JM, Ding F, Yakobson BI, Harutyunyan AR. Low-Temperature Single-Wall Carbon Nanotubes Synthesis: Feedstock Decomposition Limited Growth. J Am Chem Soc. 2008;130:11840-1.

[18] Shukla B, Saito T, Ohmori S, Koshi M, Yumura M, Iijima S. Interdependency of Gas Phase Intermediates and Chemical Vapor Deposition Growth of Single Wall Carbon Nanotubes. Chem Mater. 2010;22:6035-43.

[19] Miyauchi Y, Chiashi S, Murakami Y, Hayashida Y, Maruyama S. Fluorescence spectroscopy of single-walled carbon nanotubes synthesized from alcohol. Chem Phys Lett. 2004;387:198-203.

[20] Lu C, Liu J. Controlling the Diameter of Carbon Nanotubes in Chemical Vapor Deposition Method by Carbon Feeding. J Phys Chem B. 2006;110:20254-7.

[21] Hafner JA, Bronikowski MJ, Azamian BR, Nikolaev P, Rinzler AG, Colbert DT, et al. Catalytic growth of single-wall carbon nanotubes from metal particles. Chem Phys Lett. 1998;296(1-2):195-202.

[22] Nessim GD, Seita M, Plata DL, O'Brien KP, Hart AJ, Meshot ER, et al. Precursor gas chemistry determines the crystallinity of carbon nanotubes synthesized at low temperature. Carbon. 2011;49:804-10.

[23] Jung M, Eun KY, Lee JK, Baik YJ, Lee KR, Park JW. Growth of carbon nanotubes by chemical vapor deposition. Diamond Rel Mater. 2001;10:1235-40.

[24] Ci L, Xie S, Tang D, Yan X, Li Y, Liu Z, et al. Controllable growth of single wall carbon nanotubes by pyrolizing acetylene on the floating iron catalysts. Chem Phys Lett. 2001;349:191-5.

[25] Maruyama S, Kojima R, Miyauchi Y, Chiashi S, Kohno M. Low-temperature synthesis of high-purity single-walled carbon nanotubes from alcohol. Chem Phys Lett. 2002;360:229-34.

[26] Shukla B, Saito T, Yumura M, Iijima S. An efficient carbon precursor for gas phase growth of SWCNTs. Chem Comm. 2009;2009:3422-4.

[27] Hung W-H, Bernasek SL. Adsorption and decomposition of ethylene and acetylene on Fe(100). Surf Sci. 1995;339:272-90.

[28] Xiang R, Einarsson E, Okawa J, Miyauchi Y, Maruyama S. Acetylene-Accelerated Alcohol Catalytic Chemical Vapor Deposition Growth of Vertically Aligned Single-Walled Carbon Nanotubes. J Phys Chem C. 2009;113:7511-5. 
[29] Zhong G, Hofmann S, Yan F, Telg H, Warner JH, Eder D, et al. Acetylene: A Key Growth Precursor for Single-Walled Carbon Nanotube Forests. J Phys Chem C. 2009;113:17321-5.

[30] Eres G, Kinkhabwala AA, Cui H, Geohegan DB, Puretzky AA, Lowndes D. Molecular Beam-Controlled Nucleation and Growth of Vertically Aligned Single-Wall Carbon Nanotube Arrays. J Phys Chem B. 2005;109:16684-94.

[31] Xu Y-Q, Flor E, Schmidt H, Smalley RE, Hauge RH. Effects of atomic hydrogen and active carbon species in $1 \mathrm{~mm}$ vertically aligned single-walled carbon nanotube growth. Appl Phys Lett. 2006;89:123116/1-/3.

[32] Plata DL, Meshot ER, Reddy CM, Hart AJ, Gschwend PM. Multiple Alkynes React with Ethylene To Enhance Carbon Nanotube Synthesis, Suggesting a Polymerization-like Formation Mechanism. ACS Nano. 2010;4(12):7185-92.

[33] Jourdain V, Bichara C. Current understanding of the growth of carbon nanotubes in catalytic chemical vapour deposition. Carbon. 2013;58:2-39.

[34] Kroto HW. The stability of the fullerenes Cn, with $\mathrm{n}=24,28,32,36,50,60$ and 70 . Nature. 1987;329:529-31.

[35] Saito Y. Nanoparticles and filled nanocapsules. Carbon. 1995;33(7):979-88.

[36] Harris PJF. Solid state growth mechanisms for carbon nanotubes. Carbon. 2007;45:229-39.

[37] Takagi D, Homma Y, Hibino H, Suzuki S, Kobayashi Y. Single-Walled Carbon Nanotube Growth from Highly Activated Metal Nanoparticles. Nano Lett. 2006;6(12):2642-5.

[38] Takagi D, Hibino H, Suzuki S, Kobayashi Y, Homma Y. Carbon Nanotube Growth from Semiconductor Nanoparticles. Nano Lett. 2007;7(8):2272-5.

[39] Liu J, Wang C, Tu X, Liu B, Chen L, Zheng M, et al. Chirality-controlled synthesis of single-wall carbon nanotubes using vapour-phase epitaxy. Nat Commun. 2012;3:1199.

[40] Wang B, Poa CHP, Wei L, Li L-J, Yang Y, Chen Y. (n,m) Selectivity of Single-Walled Carbon Nanotubes by Different Carbon Precursors on Co-Mo Catalysts. J Am Chem Soc. 2007;129:9014-9.

[41] Yasuda S, Futaba DN, Yamada T, Yumura M, Hata K. Gas Dwell Time Control for Rapid and Long Lifetime Growth of Single-Walled Carbon Nanotube Forests. Nano Lett. 2011;11:3617-23.

[42] Plata DL, Hart AJ, Reddy CM, Gschwend PM. Early evaluation of potential environmental impacts of carbon nanotube synthesis by chemical vapor deposition. Environ Sci Technol. 2009;43(21):8367-73. 

Carbon Nanotubes. J Phys Chem C. 2010;114:2398-402.

[44] Harutyunyan AR, Awasthi N, Jiang A, Setyawan W, Mora E, Tokune T, et al. Reduced Carbon Solubility in Fe Nanoclusters and Implications for the Growth of Single-Walled Carbon Nanotubes. Phys Rev Lett. 2008;100:195502/1-4.

[45] Hofmann S, Sharma R, Ducati C, Du G, Mattevi C, Cepek C, et al. In situ Observations of Catalyst Dynamics during Surface-Bound Carbon Nanotube Nucleation. Nano Lett. 2007;7(3):602-8.

[46] Ohta Y, Okamoto Y, Page AJ, Irle S, Morokuma K. Quantum Chemical Molecular Dynamics Simulation of Single-Walled Carbon Nanotube Cap Nucleation on an Iron Particle. ACS Nano. 2009;3(11):3413-20.

[47] Anisimov AS, Nasibulin AG, Jiang H, Launois P, Cambedouzou J, Shandakov SD, et al. Mechanistic investigations of single-walled carbon nanotube synthesis by ferrocene vapor decomposition in carbon monoxide. Carbon. 2010;48:380-8.

[48] Eres G, Rouleau CM, Yoon M, Puretzky AA, Jackson JJ, Geohegan DB. Model for Self-Assembly of Carbon Nanotubes from Acetylene Based on Real-Time Studies of Vertically Aligned Growth Kinetics. J Phys Chem C. 2009;113:15484-91.

[49] Yoshida H, Takeda S, Uchiyama T, Kohno H, Homma Y. Atomic-Scale In-situ Observation of Carbon Nanotube Growth from Solid State Iron Carbide Nanoparticles. Nano Lett. 2008;8(7):2082-6.

[50] Frenklach M, Wang H. Detailed modeling of soot particle nucleation and growth. Symposium (International) on Combustion. 1991;23(1):1559-66.

[51] Richter H, Howard JB. Formation of polycyclic aromatic hydrocarbons and their growth to soot - a review of chemical reaction pathways. Prog Ener Comb Sci. 2000;26:565-608.

[52] Kislov VV, Sadovnikov AI, Mebel AM. Formation mechanism of polycyclic aromatic hydrocarbons beyond the second aromatic ring. The journal of physical chemistry A. 2013;117(23):4794-816.

[53] Irle S, Ohta Y, Okamoto Y, Page AJ, Wang Y, Morokuma K. Milestones in Molecular Dynamics Simulations of Single-Walled Carbon Nanotube Formation: A Brief Critical Review. Nano Res. 2009;2:755-67.

[54] Tessonier J-P, Su DS. Recent Progress on the Growth Mechanism of Carbon Nanotubes: A Review. Chem Sus Chem. 2011;4:824-47.

[55] Elliott JA, Shibuta Y, Amara H, Bichara C, Neyts EC. Atomistic modelling of CVD synthesis of carbon nanotubes and graphene. Nanoscale. 2013;5(15):6662-76. 
[56] Neyts EC, van Duin ACT, Bogaerts A. Changing Chirality during Single-Walled Carbon Nanotube Growth: A Reactive Molecular Dynamics/Monte Carlo Study. J Am Chem Soc. 2011;133:17225-31.

[57] Yuan Q, Hu H, Ding F. Threshold Barrier of Carbon Nanotube Growth. Phys Rev Lett. 2011;107:156101/1-5.

[58] Gomez-Gualdron DA, McKenzie GD, Alvarado JFJ, Balbuena PB. Dynamic Evolution of Supported Metal Nanocatalyst/Carbon Structure during Single-Walled Carbon Nanotube Growth. ACS Nano. 2012;6:720-35.

[59] Gutsev GL, Weatherford CA, Jena P, Johnson E, Ramachandran BR. Structural Patterns in Carbon Chemisorption on an Icosahedral 2 Iron Cluster. J Phys Chem C. 2012;116:7050-61.

[60] Kim J, Page AJ, Irle S, Morokuma K. The Dynamics of Local Chirality during SWCNT Growth: Armchair versus Zigzag Nanotubes. J Am Chem Soc. 2012;134:9311-9.

[61] Gómez-Gualdrón DA, Beetge JM, Burgos JC, Balbuena PB. Effects of Precursor Type on the CVD Growth of Single-Walled Carbon Nanotubes. J Phys Chem C. 2013;117(20):10397-409.

[62] Frauenheim T, Weich F, Köhler T, Uhlmann S, Porezag D, Seifert G. Density-functional-based construction of transferable nonorthogonal tight-binding potentials for Si and SiH. Phys Rev B. 1995;52(11492-11501).

[63] Elstner M, Porezag D, Jungnickel G, Elsner J, Haugk M, Frauenheim T, et al. Self-consistent-charge density-functional tight-binding method for simulations of complex materials properties. Phys Rev B. 1998;58:7260-8.

[64] Zheng G, Witek H, Bobadova-Parvanova P, Irle S, Musaev DG, Prabhakar R, et al. Parameterization of Transition Metal Elements for the Spin-Polarized Self-Consistent-Charge Density-Functional Tight-Binding Method: 1. Parameterization of Ti, Fe, Co, and Ni. J Chem Theory Comput 2007;3:1349-67

[65] Kohler C, Seifert G, Gerstmann U, Elstner M, Overhof H, Frauenheim T. Approximate density-functional calculations of spin densities in large molecular systems and complex solids. Phys Chem Chem Phys. 2001;3:5109-14.

[66] Irle S, Zheng G, Wang Z, Morokuma K. The C60 Formation Puzzle "Solved": QM/MD Simulations Reveal the Shrinking Hot Giant Road of the Dynamic Fullerene Self-Assembly Mechanism. J Phys Chem B. 2006:14531-45.

[67] Page AJ, Ohta Y, Irle S, Morokuma K. Mechanisms of Single-Walled Carbon Nanotube Nucleation, Growth and Healing Determined Using QM/MD Methods Acc Chem Res. 2010;43:1375-85. 
[68] Wang Y, Page AJ, Nishimoto Y, Qian H-J, Morokuma K, Irle S. Template Effect in the Competition Between Haeckelite and Graphene Growth on Ni(111): Quantum Chemical Molecular Dynamics Simulations. J Am Chem Soc. 2011;133:18837-42.

[69] Irle S, Page AJ, Saha B, Wang Y, Chandrakumar KRS, Nishimoto Y, et al. Atomistic mechanism of carbon nanostructure self-assembly as predicted by nonequilibrium QM/MD simulations. In: Leszczynski J, Shukla MK, eds. Practical Aspects of Computational Chemistry II: An Overview of the Last Two Decades and Current Trends: Springer-European Academy of Sciences 2012.

[70] Weinert M, Davenport JW. Fractional Occupations and Density-Functional Energies and Forces. Phys Rev B. 1992;45(23):13709-12.

[71] Niklasson AMN. A note on the Pulay force at finite electronic temperature. J Chem Phys. 2008;129:244107/1-5.

[72] Martyna GJ, Klein ML, Tuckerman M. Nose-Hoover chains: The canonical ensemble via continuous dynamics. J Chem Phys. 1992;97:2635-43.

[73] Ohta Y, Okamoto Y, Irle S, Morokuma K. Rapid Growth of a Single-Walled Carbon Nanotube on an Iron Cluster: Density-Functional Tight-Binding Moleculer Dynamics Simulations. ACS Nano. 2008;2:1437-44.

[74] Ohta Y, Okamoto Y, Irle S, Morokuma K. Temperature Dependence of Iron-Catalyzed Continued Single-Walled Carbon Nanotube Growth Rates: Density Functional Tight-Binding Molecular Dynamics Simulations. J Phys Chem C. 2009;113(1):159-69.

[75] Ohta Y, Okamoto Y, Irle S, Morokuma K. Single-Walled Carbon Nanotube Growth from a Cap Fragment on an Iron Nanoparticle: Density-Functional Tight-Binding Molecular Dynamics Simulations. Phys Rev B. 2009;79(19):195415.

[76] Page AJ, Ohta Y, Okamoto Y, Irle S, Morokuma K. Defect Healing during Single-Walled Carbon Nanotube Growth: A Density-Functional Tight-Binding Molecular Dynamics Investigation. J Phys Chem C. 2009;113(47):20198-207.

[77] Fukui K. The Patch of Chemical Reactions - The IRC Approach. Acc Chem Res. 1981;14:363-8.

[78] Frisch MJ, Trucks GW, Schlegel HB, Scuseria GE, Robb MA, Cheeseman JR, et al. GAUSSIAN 03. C.01 ed. Wallingford, CT: Gaussian, Inc. 2004.

[79] Soler JM, Artacho E, Gale JD, Garcia A, Junquera J, Ordejon P, et al. The SIESTA Method for $\mathrm{Ab}$ Initio Order-N Materials Simulation. $\mathrm{J}$ Phys: Condens Matter. 2002;14:2745-79.

[80] Perdew JP, Burke K, Ernzerhof M. Generalized Gradient Approximation Made 
Simple. Phys Rev Lett. 1996;77(18):3865-8.

[81] Perdew JP, Burke K, Ernzerhof M. Generalized Gradient Approximation Made Simple [Phys. Rev. Lett. 77, 3865 (1996)]. Phys Rev Lett. 1997;78(7):1396.

[82] Troullier N, Martins JL. Efficient pseudopotentials for plane-wave calculations. Phys Rev B. 1991;43:1993-2006.

[83] Lo JMH, Ziegler T. Theoretical Studies of the Formation and Reactivity of C2 Hydrocarbon Species on the Fe(100) Surface. J Phys Chem C. 2007;111:13149-62.

[84] Vasenkov AV, Sengupta D, Frenklach M. Multiscale Modeling Catalytic Decomposition of Hydrocarbons during Carbon Nanotube Growth. J Phys Chem B. 2009; 113:1877-82.

[85] Okamoto Y, Kawamura Y, Ohta Y, Page AJ, Irle S, Morokuma K. Self-Consistent-Charge Density-Functional Tight-Binding/MD Simulation of Transition Metal Catalyst Particle Melting and Carbide Formation. J Comput Theor Nanosci. 2011;8:1755-63.

[86] Saha B, Shindo S, Irle S, Morokuma K. Quantum chemical molecular dynamics simulations of dynamic fullerene self-assembly in benzene combustion. ACS Nano. 2009;3:2241-57.

[87] Saha B, Irle S, Morokuma K. Formation mechanism of polycyclic aromatic hydrocarbons in benzene combustion: Quantum chemical molecular dynamics simulations. J Chem Phys. 2010;132:224303/1-/11.

[88] List B. Organocatalysis: A Complementary Catalysis Strategy Advances Organic Synthesis. Adv Synth Catal. 2004;346:1021.

[89] Prigogine I, Stengers I. Order out of Chaos: Man's new dialogue with nature. Toronto: Bantam Books; 1984.

[90] Qian H-J, van Duin ACT, Morokuma K, Irle S. Reactive Molecular Dynamics Simulation of Fullerene Combustion Synthesis: ReaxFF vs DFTB Potentials. J Chem Theory Comput. 2011;7(2040-2048).

[91] Hammond GS. A Correlation of Reaction Rates. J Am Chem Soc. 1955;1955:334-8.

[92] Wang XK, Lin XW, Meshleh M, Jarrold MF, Dravid VP, Ketterson JB, et al. The effect of hydrogen on the formation of carbon nanotubes and fullerenes. $J$ Mater Res. 1995;10:1977-83.

[93] Takehara H, Fujiwara M, Arikawa M, Diener MD, Alford JM. Experimental study of industrial scale fullerene production by combustion synthesis. Carbon. 2005;43:311-9.

[94] Li H-B, Page AJ, Irle S, Morokuma K. Theoretical Insights for Chirality-Controlled 
SWCNT Growth from a Cycloparaphenylene Template. Chem Phys Chem. 2012;13:1479-85.

[95] Li H, Page AJ, Irle S, Morokuma K. Single-walled Carbon Nanotube Growth from Chiral Carbon Nanorings: Prediction of Chirality and Diameter Influence on Growth Rates. J Am Chem Soc. 2012;134:15887-96.

[96] Omachi H, Nakayama T, Takahashi E, Segawa Y, Itami K. Initiation of carbon nanotube growth by well-defined carbon nanorings. Nat Chemistry. 2013;5(7):572-6.

[97] Zhu RS, Xu ZF, Lin MC. Ab initio studies of alkyl radical reactions: Combination and disproportionation reactions of $\mathrm{CH} 3$ with $\mathrm{C} 2 \mathrm{H} 5$, and the decomposition of chemically activated C3H8. J Chem Phys. 2004;120(14):6566-73. 